Winthrop University

Digital Commons @ Winthrop

University

Spring 5-2021

\title{
Mindful Eating and Perceived Stress in College Students
}

Emily G. Garrett

Winthrop University, eggarrett20@gmail.com

Follow this and additional works at: https://digitalcommons. winthrop.edu/graduatetheses

Part of the Behavior and Behavior Mechanisms Commons, and the Human and Clinical Nutrition Commons

\section{Recommended Citation}

Garrett, Emily G., "Mindful Eating and Perceived Stress in College Students" (2021). Graduate Theses. 129. https://digitalcommons.winthrop.edu/graduatetheses/129

This Thesis is brought to you for free and open access by the The Graduate School at Digital Commons @ Winthrop University. It has been accepted for inclusion in Graduate Theses by an authorized administrator of Digital Commons @ Winthrop University. For more information, please contact digitalcommons@mailbox.winthrop.edu. 
March, 2021

To the Dean of the Graduate School:

We are submitting a thesis written by Emily G. Garrett entitled Mindful Eating and Perceived Stress in College Students. We recommend acceptance in partial fulfillment of the requirements for the degree of Master of Science in Human Nutrition.

Jessie Hoffman, Thesis Advisor

Ashley Licata, Committee Member

Hope Lima, Committee Member

Karin Evans, Committee Member

Courtney Guenther, Committee Member

Takita Sumter, Dean, College of Arts and Sciences

Jack E. DeRochi, Dean, Graduate School 


\section{MINDFUL EATING AND PERCEIVED STRESS IN COLLEGE STUDENTS}

A Thesis Presented to the Faculty

Of the

College of Arts and Sciences In Partial Fulfillment

Of the Requirements for the Degree

Of Master of Science

In Human Nutrition

Winthrop University

May, 2021

By

Emily G. Garrett 


\begin{abstract}
Background: Evidence suggests that in college student populations, stress levels often manifest as maladaptive eating and/or functional gastrointestinal disorders. These conditions can degrade wellbeing and academic performance if not addressed.

Research aim/question(s): The purpose of this study was to examine the relationships between students' perceived stress, their overall mindfulness, and mindful eating patterns. Gastrointestinal $(\mathrm{GI})$ symptoms and bowel habits were also investigated to determine whether these factors were stress-related or influenced mindfulness behaviors.
\end{abstract}

Materials and Methods: An online survey was conducted during the 2020-2021 academic year. Demographic information, including smoking, alcohol, and drug use patterns, was gathered in addition to participants completing the validated Perceived Stress Scale (PSS) and Mindfulness Attention Awareness Scale (MAAS) and a non-validated Mindful Eating Self-Assessment (MESA).

Descriptive statistics and Pearson correlations were obtained using SPSS.

Results: Statistically significant negative correlations were observed between scores on the PSS and MAAS $(r=-0.471, p<0.01)$, as well as between the PSS and MESA $(r=-0.314, p<0.01)$. A significant negative correlation was found between smoking and perceived stress $(r=-0.191, p=0.047)$. However, no other significant relationships were observed between substance use and stress, mindfulness, or mindful eating. Stress and pain frequency were positively correlated ( $p=0.001$ ), but no other significant correlations were found between stress, mindfulness, or mindful eating and GI parameters.

Conclusion: Overall, the observation of an inverse relationship between stress and both mindfulness and mindful eating in college students highlights a need for future studies and mindful eating interventions in this population. 


\section{Acknowledgements}

I would like to give my sincere appreciation to my thesis advisor, Dr. Jessie Hoffman, for her guidance and patience throughout the execution of this project. I would also like to thank the members of my thesis committee: Dr. Hope Lima, Dr. Ashley Licata, Dr. Courtney Guenther, and Mrs. Karin Evans. I would specifically like to thank Mrs. Karin Evans for helping me to develop research ideas that led to the conception of this study. This thesis would not exist without her passion and dedication. Dr. Hope Lima was instrumental in troubleshooting and refining study design, and I would like to thank her for pushing me to strive for scientific excellence during my time at Winthrop. I am extremely grateful to Dr. Ashley Licata for her assistance with data analysis. I would also like to thank Dr. Courtney Guenther for her support and encouragement, as her kind words and perspective have allowed me to press forward with confidence. I also owe my thanks to Eden Crain and Mika Doyle, who assisted with the initial stages of this project. Lastly, I would like to thank my family and close friends who offered their support and encouragement throughout this process. 


\section{Table of Contents}

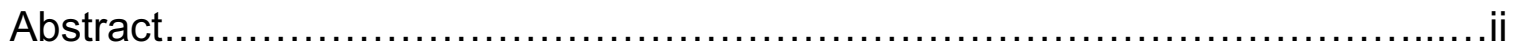

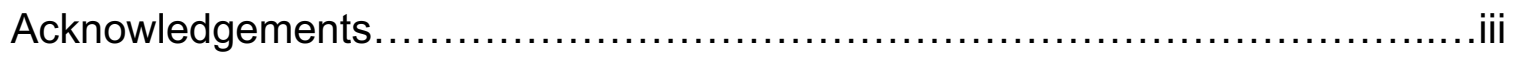

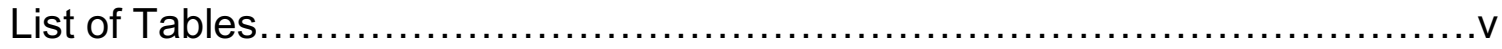

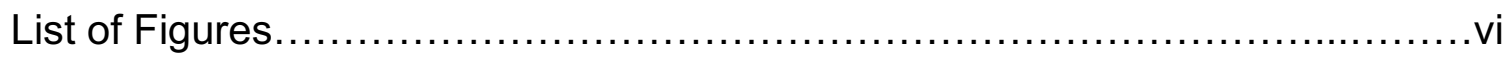

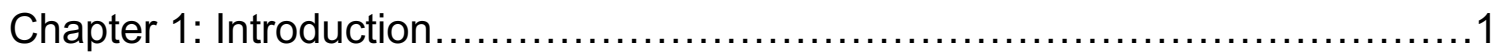

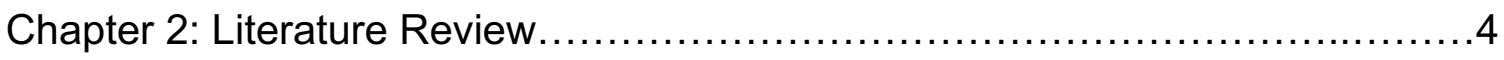

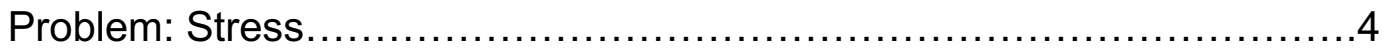

Temporary Solution: Maladaptive Eating............................... 14

Corrective Action: Mindful Eating ................................. 19

Research Gaps....................................................... 27

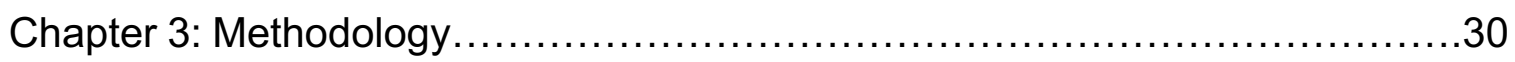

Chapter 4: Results....................................................

Chapter 5: Discussion.................................................

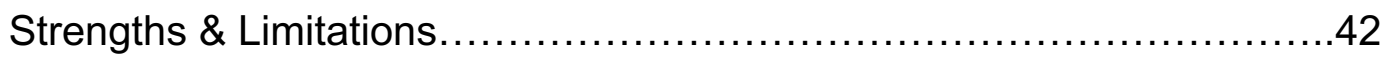

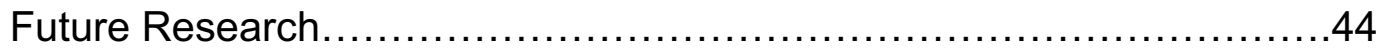

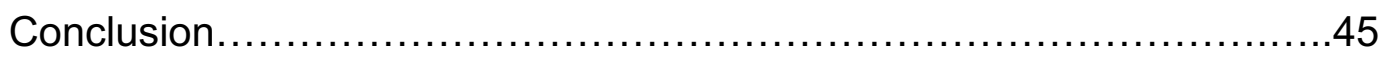

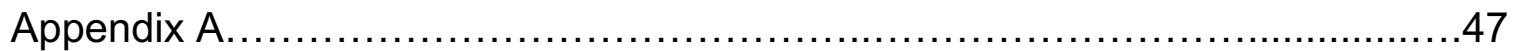

Appendix B........................................................60

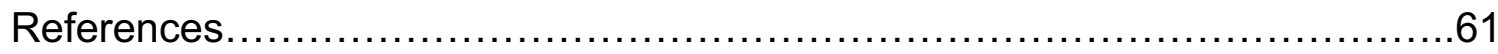




\section{List of Tables}

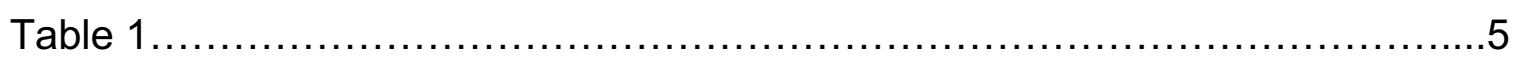

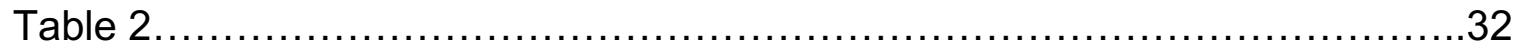

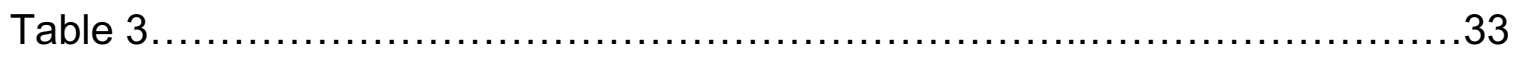

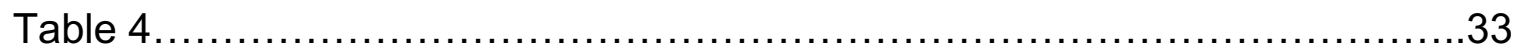

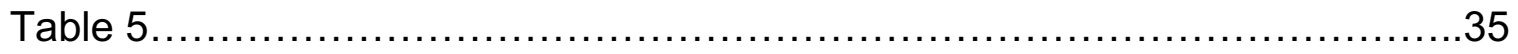

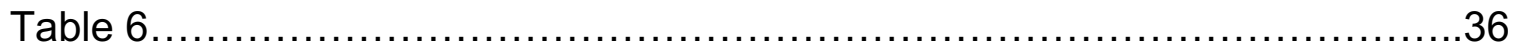




\section{List of Figures}

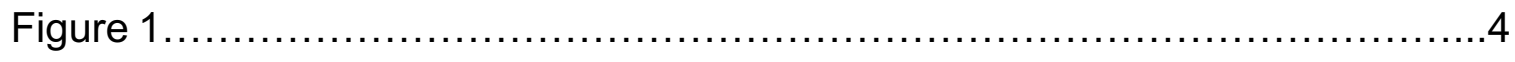

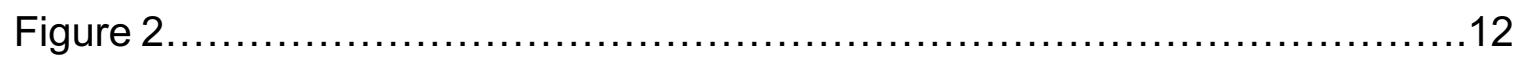

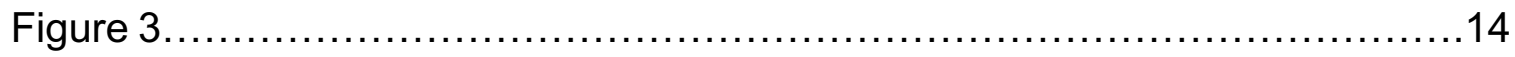

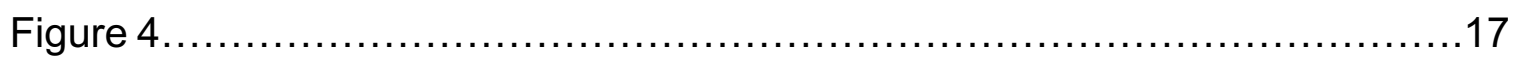

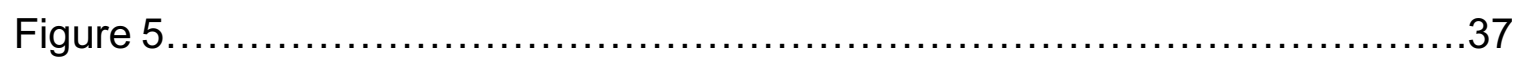

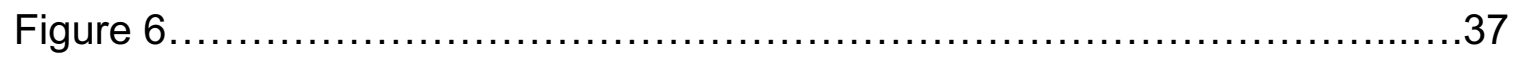




\section{Chapter 1: Introduction}

Modern college student life places ever-increasing demands on young adults, as there is a growing list of information and skills required to thrive professionally. As technology advances faster than one generation can teach another, students in the last decade have had to teach themselves how to manage the overstimulating lifestyle these technologies create, along with the constantly expanding realms of knowledge and experience required to stand out in any field.

Occupational stress has been investigated frequently in the literature,$^{1-5}$ and there is a link between chronic stress and undesirable health outcomes. ${ }^{6,7}$ There is some translation of this work to college students and young adults in general, ${ }^{8-11}$ but there is not yet enough information available to fully understand the ways that this population processes constant stressors. Therefore, there is a need for more interventions targeted toward chronically stressed college students.

Chronic stress can lead to the adoption of maladaptive eating patterns which ultimately have negative consequences on nutrition and overall health. ${ }^{12}$ Maladaptive eating behaviors are difficult to define since they can often appear similar to healthy or adaptive eating behaviors. However, publications within the last five to ten years have begun to delineate subcategories of maladaptive eating behavior, such as emotional, external, and restrained eating or disinhibited eating. ${ }^{13}$ These subcategories are helpful for determining the necessary components of an effective mindfulness-based intervention (MBI) for eating behaviors. Mindfulness, or paying attention to one's sensations and environment in the present moment, has been investigated for stress reduction as well as eating 
behavior regulation. ${ }^{3,14-18}$ Research on MBls for eating behaviors has primarily been conducted within the last decade, which means that there are still numerous areas to research.

Additionally, stress commonly presents in the form of gastrointestinal disturbances, ${ }^{19}$ as the enteric nervous system (ENS) in the intestines is tied intimately to the central nervous system $(\mathrm{CNS}) \cdot{ }^{20-23}$ The relationship between these two divisions of the nervous system is termed the 'gut-brain axis', and it has been a highly popular research focus within the last decade. ${ }^{24-27}$ While there is still much to be understood about the gut-brain axis, there is evidence to suggest an effect of gut-brain communication on the stress response, which is operated by the hypothalamic-pituitary-adrenal (HPA) axis..$^{20,28-31}$ The HPA axis controls the hormonal cascade that produces adrenal hormones, such as cortisol and epinephrine. ${ }^{20}$ These hormones are responsible for the alterations in neurochemistry that, when occurring at high levels, result in altered behavior to bring the body back to homeostasis. ${ }^{20}$ These behaviors can be adaptive, leading to long-term health, or maladaptive, leading to long-term dysregulation or disease.

When the body is constantly releasing stress hormones, there is little to no ability to reestablish homeostasis, and any improvement of physiological balance is reversed by the next increase in cortisol. Dysregulated gastrointestinal function is a common presentation in young adults, ${ }^{32}$ and functional gastrointestinal disorders (FGID) have become a budding topic of investigation among this population due to their increased levels of stress. ${ }^{10,33}$ The field of psychogastroenterology addresses the overlap of gastrointestinal disturbances 
and abnormal behavior patterns, bridging the gap between physical and mental repercussions of chronic stress. ${ }^{34,35}$ While chronic stress often manifests physically, mental symptoms such as anxiety, depression, and maladaptive coping behaviors have been identified in the literature as well. ${ }^{12,36,37}$

The purpose of this study was to investigate the degree of stress experienced by students at Winthrop University and to determine if there is any correlation between students' perceived stress and mindfulness as well as mindful eating patterns. This study will help to establish a foundation for future research on stress among Winthrop students. Additionally, this study will serve as a needs assessment for future implementation of mindfulness-based eating interventions. Gastrointestinal parameters were gathered to determine whether GI factors were impacted by stress or influenced students' degree of mindfulness. Additionally, information about smoking, alcohol intake, and drug use was collected to determine whether these behaviors correlate with stress or mindful eating. 


\section{Chapter 2: Literature Review}

\section{Problem: Stress}

The Stress Response

Stress is an increasingly prominent health risk in society, as several symptoms and diseases are manifested as a result of continuous unresolved stress on the mind and body. ${ }^{31}$ Physiological stress is detected by observing phenotypic symptoms or measuring biomarkers that indicate increased activity of the hypothalamic-pituitary-adrenal (HPA) axis. ${ }^{38}$ The HPA axis is composed of the hypothalamus and pituitary gland located within the brain, as well as the adrenal glands on top of the kidneys (see Figure 1). The hypothalamus is important for regulating the body's energy balance, and it releases precursors to gut hormones that regulate food intake. ${ }^{38}$ The pituitary gland is responsible for regulating numerous other body functions indirectly through the secretion of signaling hormones (see Table 1). ${ }^{38,39}$

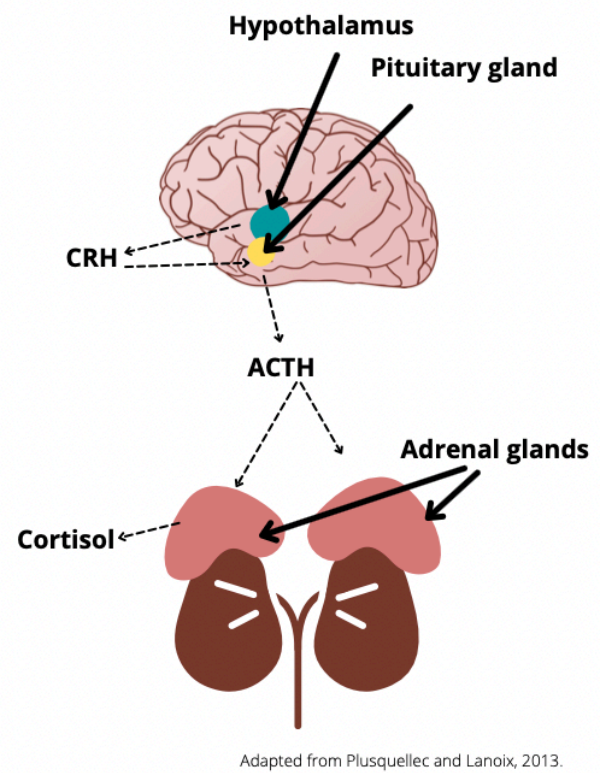

Figure 1. The HPA axis. ${ }^{38,40}$ 
Table 1. Signaling hormones released from the pituitary gland. ${ }^{38,39}$

\begin{tabular}{ll}
\hline Hormone & \multicolumn{1}{c}{ Function } \\
\hline Adrenocorticotropic hormone (ACTH) & $\begin{array}{l}\text { Triggers adrenal glands to produce } \\
\text { cortisol }\end{array}$ \\
\cline { 2 - 2 } Follicle-stimulating hormone (FSH) & $\begin{array}{l}\text { Aids spermatogenesis in men and } \\
\text { estrogen production in women }\end{array}$ \\
\cline { 2 - 2 } Luteinizing hormone (LH) & $\begin{array}{l}\text { Triggers ovulation in women and } \\
\text { testosterone production in men }\end{array}$ \\
\cline { 2 - 2 } Growth hormone (GH) & $\begin{array}{l}\text { Contributes to muscle and bone } \\
\text { production; regulates distribution of } \\
\text { body fat }\end{array}$ \\
\cline { 2 - 2 } Prolactin (PRL) & $\begin{array}{l}\text { Aids production of breast milk; } \\
\text { stimulates production of other } \\
\text { reproductive hormones in men and } \\
\text { women }\end{array}$ \\
\cline { 2 - 2 } Thyroid-stimulating hormone (TSH) & $\begin{array}{l}\text { Stimulates thyroid to produce thyroid } \\
\text { hormones which regulate } \\
\text { metabolism, energy balance, and } \\
\text { neuronal signaling }\end{array}$ \\
\cline { 2 - 2 } Oxytocin & $\begin{array}{l}\text { Triggers labor and breast milk } \\
\text { production; facilitates bonding }\end{array}$ \\
\cline { 2 - 2 } Anti-diuretic hormone (ADH) & $\begin{array}{l}\text { Regulates fluid balance and sodium } \\
\text { levels }\end{array}$ \\
\hline
\end{tabular}

Corticotropin-releasing hormone $(\mathrm{CRH})$ is released from the hypothalamus in response to stress, which triggers the pituitary gland to release adrenocorticotropic hormone (ACTH), which acts as a signaling hormone to instruct the adrenal glands to produce cortisol. ${ }^{38}$ Cortisol is a catabolic hormone that aids in breaking down lean body mass to increase available energy needed in the "fight or flight" response to a stressor. ${ }^{7}$ In acute stress situations, this hormone is part of an adaptive and necessary response for survival, but when a stressor is continuous and keeps the body in a constant state of heightened stress, the release of cortisol takes on a damaging effect by causing decreased digestion and absorption, loss of lean body mass, and typically increased fat mass as a protective mechanism to build up energy stores for an emergency "fight or flight" 
situation. ${ }^{7,22} \mathrm{~A}$ loss of lean body mass can be detrimental if it continues to the point of malnutrition, and increased fat mass can eventually influence mobility, quality of life, and metabolic health. ${ }^{41}$ For athletes, these stress-induced metabolic shifts can be a detriment to desired performance goals. ${ }^{42}$ When the HPA axis is activated, parasympathetic nervous system (PNS) functions are suppressed while sympathetic nervous system (SNS) functions are heightened. Therefore, during periods of chronic stress, all PNS functions necessary for maintaining homeostasis are compromised for an extended period of time, which pose a significant risk to long-term health outcomes. ${ }^{30}$

\section{Mindfulness}

Mindfulness is the state of being aware in the present moment while reacting neutrally to one's thoughts and environment. ${ }^{43,44} \mathrm{~A}$ key principle of mindfulness is the use of a nonjudgmental approach, which allows an individual to make observations while preventing intense emotions from clouding the objective scenario. It is used to inform the mind and body that at the present moment, "everything is okay" in an effort to detach from a stress response. In the literature, mindfulness is described in two forms: state mindfulness and trait mindfulness. Trait mindfulness is the measure of a person's built capacity for mindfulness, as opposed to state mindfulness, the degree of mindfulness they exude at one moment in time..$^{14,32,45}$ While state mindfulness may fluctuate from one minute to another, trait mindfulness is used to describe a person's overall resilience toward stressors, whether or not they are engaging in mindfulness activities in the present moment. This is comparable to the concept of measuring hemoglobin A1c (HbA1c) 
versus postprandial blood glucose, where trait mindfulness is similar to the $\mathrm{HbA1c}$, which measures average blood glucose levels over three months, and state mindfulness is similar to measuring postprandial blood glucose at one point in time. Mindfulness practices are used to increase one's state mindfulness and contribute toward greater trait mindfulness. They can take the form of breathing exercises, meditation, mindful movement, or mindful eating, as well as other nuanced applications of mindfulness to specific activities. ${ }^{43,44,46-48}$

Evidence for the use of mindfulness techniques to attenuate stress has grown significantly in recent years. ${ }^{33,49-52}$ A 2017 meta-analysis based on 45 randomized controlled trials demonstrated that three forms of meditation (Open Monitoring, Automatic Self-Transcendence, and Focused Attention) decreased blood pressure, heart rate, serum cholesterol, and serum triglyceride levels. ${ }^{53}$ Open monitoring refers to monitoring one's current surroundings with an open mind and a non-reactive stance. Automatic self-transcending refers to strict focus on an arbitrary mantra as a means to become more self-aware, where the mantra is eventually replaced with self-awareness. Focused attention involves focusing on an aspect of one's current experience, such as breathing, in order to train the mind to be present. Automatic self-transcending meditation (AST) was shown to lower systolic blood pressure, while focused attention meditation (FA) lowered serum cortisol and resting systolic blood pressure. Open monitoring meditation (OM) lowered ambulatory systolic blood pressure, resting systolic blood pressure following a stress test, and resting heart rate. ${ }^{53}$ It is important to acknowledge that 
the authors determined many studies had a high risk of bias and that some studies could not be placed into a bias risk category with full accuracy. ${ }^{53}$

Contrary to the findings of Pascoe et al., an intervention study conducted in 2018 failed to conclude that mindfulness can keep the stress response under control. However, participants who scored higher for trait mindfulness on the MAAS were mostly "non-reactors", meaning that their response to stress typically does not involve an acute increase in cortisol levels. This indicates that more research is needed to make a thorough conclusion about the role of mindfulness in stress management, as well as a deeper understanding of how individuals may vary in their physiological stress response. ${ }^{45}$

The results of chronic stress on an individual's long-term health can be seen when examining occupational stress. Several studies have utilized a work environment to measure the impact of occupational demands on individuals' cortisol production and perceived stress. ${ }^{1-3,54}$ Heckenberg et al. examined the effect of an online Mindfulness-Based Stress Reduction program on objective and subjective measures of stress in the work environment. ${ }^{54}$ They found that there was no correlation between effort-reward imbalance, overcommitment, and physiological stress markers. However, there was a positive correlation between secretory immunoglobin $A(\operatorname{sg} A)$, which is a measure of mucosal immunity, and trait mindfulness. The finding that mucosal immunity increases as overall mindfulness increases has important implications for the use of mindfulness to protect the body against infection ${ }^{54}$ While this is not directly related to the stress response, it has been established in the literature that mucosal immunity and 
inflammation in the body are heightened during times of increased stress, making the body more vulnerable to disease and infection. ${ }^{54}$ One year later, the same authors again found no correlation between effort-reward imbalance or overcommitment and any physiological markers for the stress response. There was, however, a statistically significant correlation $(p=0.01,95 \% C L)$ between slgA and trait mindfulness, which supports prior findings. ${ }^{3}$

Another occupational stress-related study looked at a group of South Korean nurses, who were asked to reflect on how their job impacts stress levels and mindfulness by filling out surveys. ${ }^{1}$ Obese nurses demonstrated MEQ scores that were significantly lower than non-obese nurses, indicating that non-obese nurses practiced mindful eating significantly more than obese nurses. Dietary intake, MEQ scores, eating disinhibition, emotional response, and emotional wellbeing were all positively associated with one another. Occupational stress was found to have a strong negative association with MEQ score, awareness, emotional response, and mental well-being. These results indicate that occupational stress has a strong impact on quality of life and mental health, as well as eating behavior. ${ }^{1}$

Several recent studies have translated research on occupational stress to college students, describing frequent heightened stress in college student populations..$^{10,33,55-57}$ A 2008 study demonstrated a statistically significant increase in college students' mindfulness after an MBSR program, ${ }^{57}$ and a 2011 study found that teaching college students transcendental mindfulness practices resulted in significantly decreased their stress, anxiety, depression, and patterns of 
perfectionism. ${ }^{55}$ Another mindfulness program called "Learning to BREATHE" was used to significantly increase quality of life (satisfaction) and decrease anxiety and depression symptoms in students transitioning into college.${ }^{56} \mathrm{~A}$ more recent study demonstrated an indirect mediating effect of positive affect via meditation intervention on food intake in college students. The intervention resulted in a stable level of positive affect as opposed to the decreased positive affect observed in the control group. ${ }^{14}$ The effectiveness of this intervention in preventing the onset of negative affect adds to the body of literature supporting mindfulness-based interventions for stress management, since maintaining a positive outlook is an important part of coping with stress. ${ }^{14}$

These individual studies align with more recent meta-analyses. One metaanalysis found statistically significant effects of interventions for reducing stress in college students compared to controls. The data favored the intervention heavily over the control treatment for programs based in mindfulness and cognitive behavioral therapy, indicating that there is a need for more interventions to combat stress within the college student demographic. ${ }^{10}$ Another meta-analysis looked at MBSR in young adult samples to examine the effects on anxiety symptoms, and after correcting for limitations and biases within individual studies, the authors found that MBSR was still favored over control treatments. ${ }^{33}$ Based on the evidence discussed, mindfulness-based interventions are a logical approach to take in providing more resources for students to manage chronic stress. 
Stress and Functional Gastrointestinal Disorders

Another way in which chronic HPA activation can damage long-term health is by influencing the development of functional gastrointestinal disorders. ${ }^{30,58} \mathrm{FGID}$ include commonly known conditions such as irritable bowel syndrome (IBS), Crohn's disease, ulcerative colitis (UC), and other nuanced conditions that do not fall under other diagnoses, but it also includes some nuanced conditions whose symptoms overlap with more common FGID and include other factors that exclude them from a diagnosis of IBS, UC, or Crohn's disease. ${ }^{30,59,60}$ FGID are not necessarily life-threatening, but their classification as chronic diseases make them particularly detrimental to both physical and psychological well-being over the course of a person's life. Their inflammatory nature causes them to inflict chronic small-scale damage to gastrointestinal tissues, brain tissue, and serum levels of several biomarkers. One key symptom of FGID is visceral pain, which is described as a dull form of referred pain for which it is difficult to pinpoint the location of origin. ${ }^{30}$ This pain is not only damaging to quality of life, but it also indicates a degree of inflammation that might have spread from the original source of pain to another area within the abdominal cavity. This inflammation on a long-term scale alters the immune system and makes the individual vulnerable to other diseases. ${ }^{61}$

The gut-brain axis is a bidirectional system of communication between the enteric nervous system (ENS) and the central nervous system (CNS) (see Figure 2). When the brain processes a stressor in the environment, it sends signals to the ENS and tells the body to focus on responding to the stressor rather than maintaining digestive processes. Alternatively, a positive event that increases 
levels of dopamine or serotonin in the brain communicates to the gut that the body is in a state of calm, and the body enters its "rest and digest" state. Signals between the ENS and CNS are mediated by the vagus nerve. ${ }^{22}$ The CNS and ENS work together to regulate release of hormones and neurotransmitters that influence GI motility. The ENS is its own separate entity, but it utilizes many of the same signaling pathways as the CNS. FGID are fueled by dysregulation of motility, inflammation, CNS innervation, and ENS innervation. ${ }^{22}$

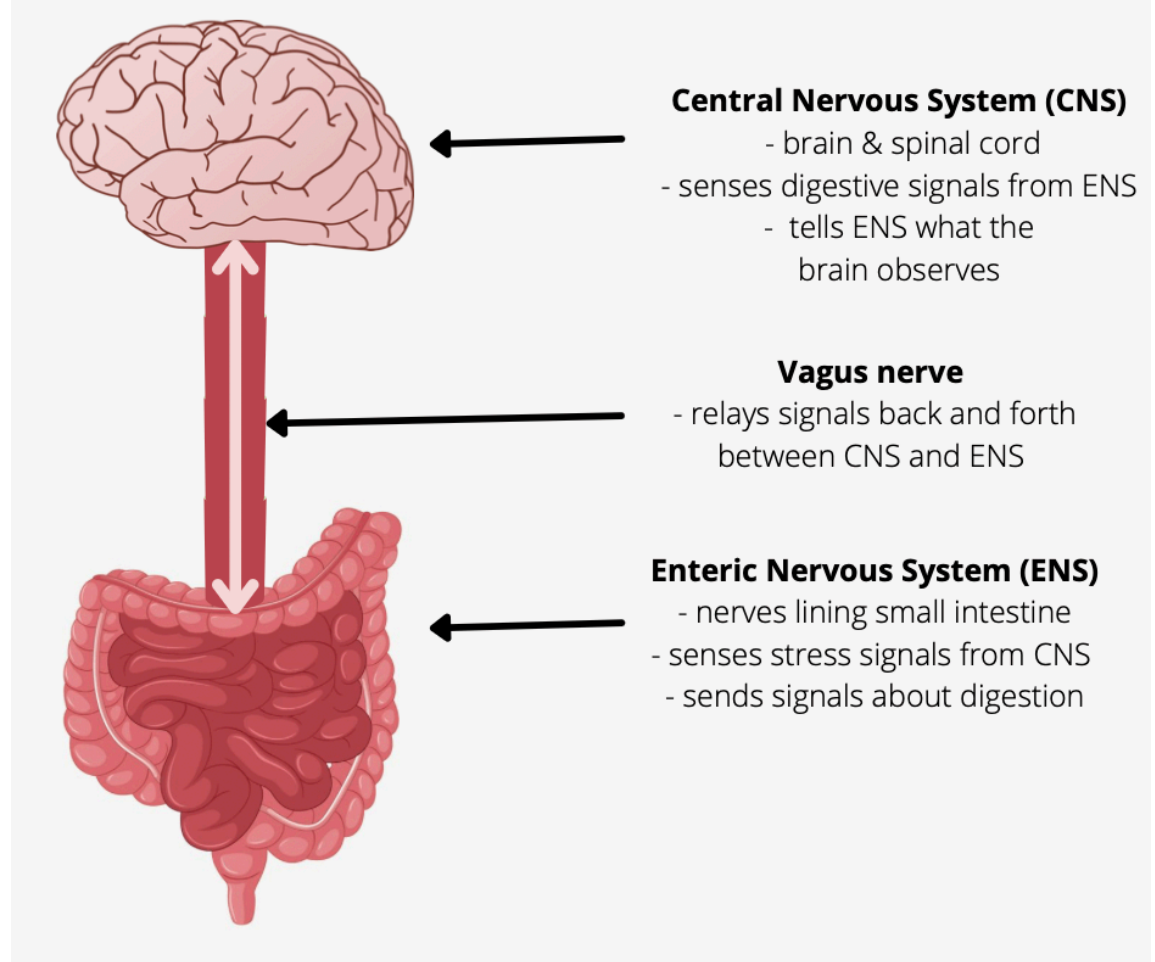

Figure 2. The gut-brain axis (highly simplified). ${ }^{22,24}$ (Intestine clip art sourced from pngtree.com.)

Neural messages from the ENS are largely influenced by a community of bacteria living in the intestines which are commonly referred to as the gut microbiome or gut microbiota. ${ }^{61}$ The distribution of various species within the gut microbiome dictates the signals that the ENS transmits to the CNS and therefore influences other physiological mechanisms like immunity, inflammation, and the 
stress response. ${ }^{22}$ Researchers have investigated potential relationships between some disease states and the proportions of certain bacterial species within the gut microbiome. These conditions include FGID, ${ }^{62}$ Alzheimer's disease, ${ }^{63,64}$ Parkinson's disease,${ }^{65}$ hypertension, ${ }^{66}$ and psychiatric conditions like anxiety and depression. ${ }^{67}$ Dysbiosis is the state of a disturbed gut microbiota that contains an abundance of harmful bacteria and a scarcity of beneficial bacteria. ${ }^{61}$ The above disease states have been connected in the literature to a lack of specific beneficial species as well as an overabundance of certain pathogenic species; however, more research is necessary in these areas to derive confident conclusions about how the gut microbiome can be modulated to treat these diseases. Evidence supports the use of probiotics to reestablish microbial balance in the gut and aid symptom resolution, although not all of the results are generalizable. ${ }^{68-71}$

Cherpak's stress-digestion-mindfulness triad is a model developed to distinguish the role of stress in inducing digestive distress, as well as the role of mindfulness in optimizing digestion (PNS dominance). ${ }^{22}$ This model acknowledges the role that the stress response has on homeostasis when stress levels are chronically high (see Figure 3). ${ }^{22}$ The stress response drains metabolic reserve, which is the capacity for the body's organs to buffer any damaging effects of the stress response. Eventually the body is no longer able to protect itself against the intense metabolic processes that normally only occur for brief periods of time. ${ }^{72} \mathrm{~A}$ 2018 study established that along with HPA axis hyperactivation, stress can also result in decreased HPA axis activation, resulting in a low level of cortisol production and a more stoic response to the stressor. ${ }^{45}$ Those who respond 
physiologically to a stressor with greater cortisol production have been described as 'reactors', while those that respond with lower cortisol production are termed 'non-reactors' ${ }^{45}$ This "non-reactivity" is a way of maintaining homeostasis after the body has exhausted its ability to combat the stressor.

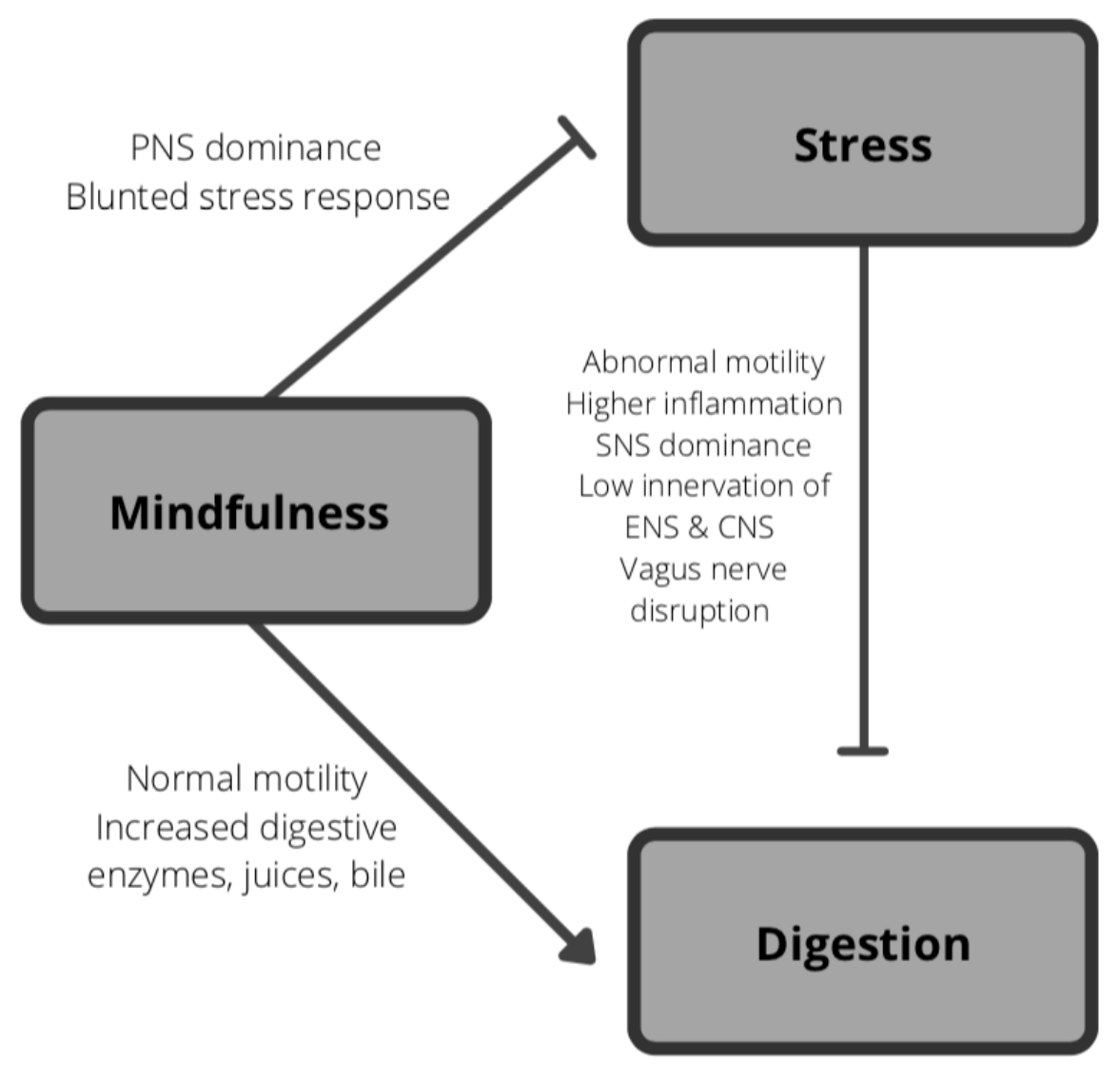

Adapted from C.E. Cherpak, 2019.

Figure 3. The stress-digestion-mindfulness triad. ${ }^{22}$

\section{Temporary Solution: Maladaptive Eating}

\section{Types of Maladaptive Eating}

Individuals experiencing intense or constant stress, whether physical or psychological, need a way to cope with stressors in order to survive, lest these stressors overcome them and render them incapacitated. The methods used to 
cope can be adaptive or maladaptive. Adaptive methods are considered healthpromoting over the long term and involve navigating the problems in a way that helps one adapt to a stressor. Conversely, maladaptive coping methods are deemed "unhealthy" due to the use of some substance or tool to ignore the stressor, which does not benefit long-term health and does not resolve the root cause of stress. Individuals using maladaptive coping often develop a dependence on the substance they use to escape, which could be food, alcohol, or drugs. ${ }^{73,74}$ In order to understand eating behaviors commonly used as maladaptive coping mechanisms, it is critical to define what adaptive coping methods look like.

Adaptive coping mechanisms aim to tackle a stressor directly, typically by addressing the source of the stressor in order to remove it. For example, in the instance that a person feels overwhelmed due to a stressful task with a quickly approaching deadline, they may notice physical symptoms of stress such as inability to focus, depression, or anxiety. ${ }^{7}$ Whereas a maladaptive response would aim to avoid the stressor entirely so that the stress is seemingly removed, such as watching television in lieu of working on the task, an adaptive response would involve pausing to detect what the root cause of the stressor is. This could look like engaging in deep breathing or a short meditation to clarify the thought processes that could be playing into physical stress. ${ }^{53}$

Adaptive and maladaptive coping mechanisms are used in many realms of behavior, but most frequently they are discussed in an applied context with drug use, alcohol use, and eating behavior. ${ }^{74-78}$ In the context of eating behavior, adaptive and maladaptive coping methods are difficult to identify accurately and 
precisely, but the research to date has attempted to shed light on several facets of the maladaptive eating response..$^{12,13,36,79}$

One key finding about the range of factors that influence one's eating behavior is that while there is a divide between adaptive and maladaptive behaviors, there are also factors outside of this spectrum that influence a person's behavior and are not necessarily correlated to the other patterns the individual exhibits. ${ }^{13}$ While there is a spectrum of eating behaviors that ranges from adaptive to maladaptive, there is more to a person's eating behaviors than a black-andwhite categorization of "good vs. bad" patterns, with each adaptive behavior having an equal and opposite maladaptive behavior. Sometimes additional influencing characteristics exist outside of that spectrum. Based on the research of Kerin et al., the description of various eating behaviors looks roughly like a spectrum of adaptive to maladaptive behaviors, but with a person's individual thought processes, attitudes, experiences, and beliefs layered on top. ${ }^{13}$ These factors may or may not correlate with where key behaviors lie on the spectrum. Essentially, the authors conclude that a person's "profile" of eating behaviors cannot be confined to a list of external behaviors - it is made richer and deeper by the underlying psychological factors that lead to observed behavior (see Figure 4). ${ }^{13}$ 


\section{Adaptive}

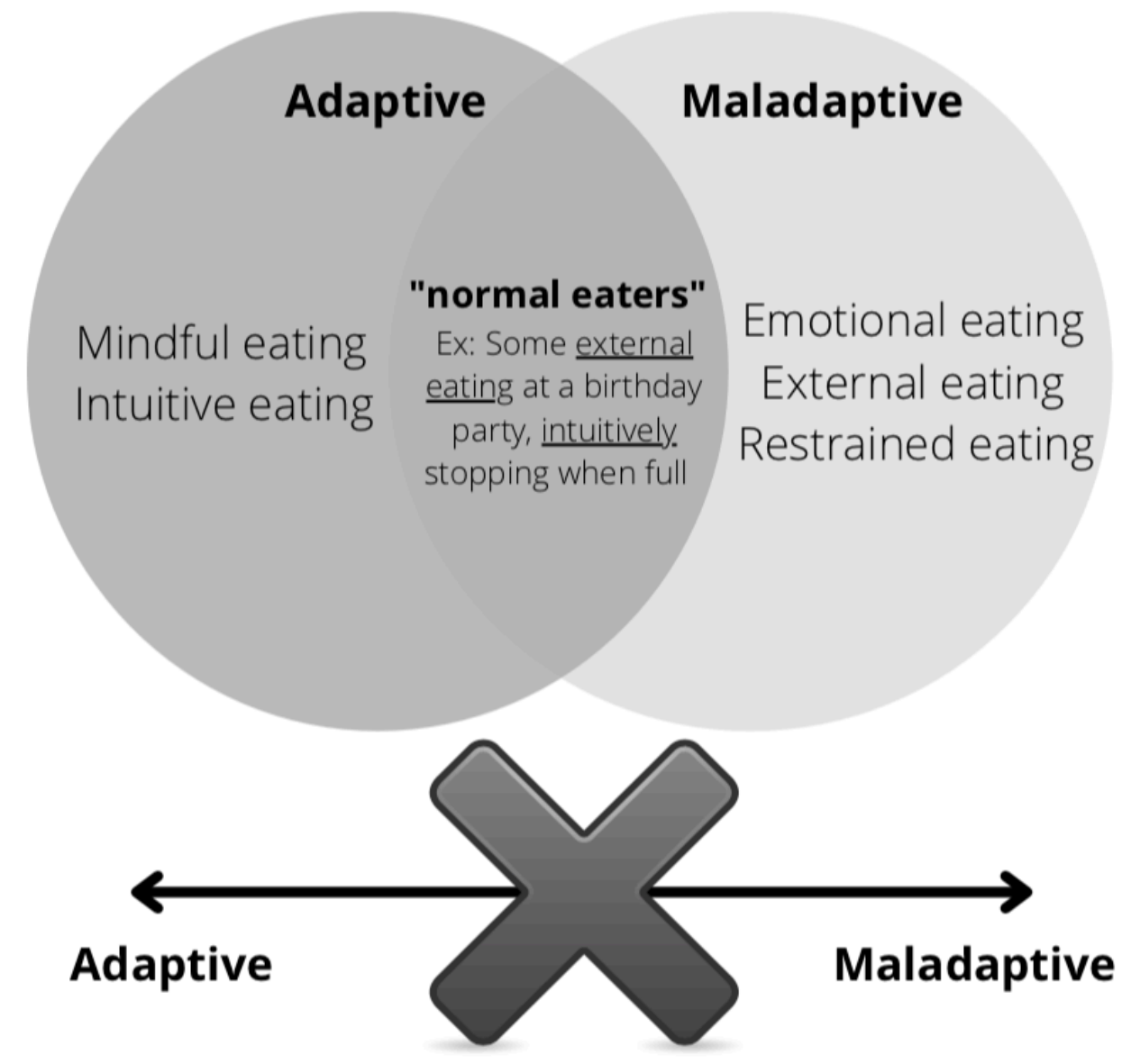

Based on concepts discussed by Kerin et al., 2019.

Figure 4. Visualization of the identified relationship between adaptive and maladaptive eating behaviors based on the findings of Kerin et al. ${ }^{13}$

There are multiple ways of categorizing maladaptive eating behaviors, but a common theme in the scientific literature involves three main types of behaviors: emotional eating, external eating, and restrained eating. All of these forms of maladaptive eating involve using some cue other than the body's hunger and satiety signals to inform eating choices. This cue can be from within the mind, as occurs with emotional eating, or it can be from outside one's own mind and body, as with external eating and restrained eating. Emotional eating involves eating in 
order to escape uncomfortable emotions. ${ }^{80}$ This could be an immediate response to an unpleasant event, or a continual suppression of negative affect from a past event. ${ }^{12,14,37,81}$ External eating cues involve the smell of food being prepared despite not being hungry, the time of day (for example, noon is typically associated with "lunchtime" whether or not hunger is present), and personal habits such as snacking consistently at $3 \mathrm{pm}$ regardless of hunger. ${ }^{12,13,37,82,83}$ Restrained eating cues involve beliefs originating outside the self, such as societal messages about body image and beauty that can lead to body image dissatisfaction and altered eating behaviors..$^{37,82,84}$

Research has expanded the ability to measure maladaptive eating behaviors with improved qualitative assessment tools as well as increased evidence for the use of physiological biomarkers. Cortisol has been explored as a physiological measure of hedonic or reward-based eating, and levels of cortisol have been positively correlated with emotional and restrained eating while negatively correlated with interoceptive awareness, which is the ability to discern the body's eating cues. ${ }^{84}$ Another study concluded that cortisol levels were positively associated with hedonic eating while negatively associated with mindful eating; it was also insignificantly correlated with reward-based eating. ${ }^{85}$

Maladaptive eating patterns can develop as a way to cope with negative physical sensations as well as negative affect. The work of O'Loughlin and Newton-John suggests that there is a statistically significant relationship between the degree of chronic pain intensity and frequency of hedonic eating. ${ }^{36}$ This relationship is mediated by stress, indicating that rather than eating due to the pain, 
individuals are eating to cope with the stress caused by the pain. $14.6 \%$ of chronic pain experienced in this sample was in the abdomen/pelvis, indicating an opportunity for future research on functional abdominal pain associated with FGID and how abdominal pain alone impacts stress-associated eating behaviors. ${ }^{36}$ This finding is complemented by a prior study concluding that individuals with $\mathrm{GI}$ disorders managed primarily by diet are more predisposed to developing disordered eating habits. ${ }^{86}$ The authors hypothesized that the progression from diagnosis of a $\mathrm{Gl}$ condition to disordered eating habits is mediated by either a "good" or "poor" mentality around the diagnosis, followed by some form of false notion about their GI condition, which leads to either restrictive, fear-based eating habits or a reckless disregard for the dietary protocol in an effort leverage the $\mathrm{Gl}$ condition for weight loss ${ }^{86}$ Conversely, several FGIDs arise secondary to eating disorders, including functional dyspepsia, functional constipation, and IBS. ${ }^{87}$ The relationship between GI symptoms and eating behaviors should be further explored in both directions in order to understand the causes and effects of maladaptive eating in populations with GI conditions.

\section{Corrective Action: Mindful Eating}

Mindful eating is an extension of mindfulness principles into the specific context of eating.$^{88}$ The role of mindful eating is to rewire the brain's default programming when that default is to use maladaptive eating as a way to survive a stressful situation. Both trait and state mindfulness have a mediating effect on "healthier eating behavior", measured by calories consumed, with "healthier" behaviors defined as decreased energy intake. ${ }^{18}$ Caloric intake alone has notable, 
but limited, relevance to the "health" of eating behavior, given the subjectivity of the term "healthy eating." However, the significance of these findings are relevant for future research that seeks to identify mechanisms of mindful eating. ${ }^{18}$

The constructs that exist under the broad realm of 'mindful eating' are still being delineated. A 2020 study validating a new mindful eating assessment tool is the first to present a more articulate and thorough definition of 'mindful eating' than that of Framson et al, who described mindful eating in 2009 as "nonjudgmental awareness of physical and emotional sensations while eating or in a food-related environment." ${ }^{88}$ There are seven components of the new definition, which is the basis for the Mindful Eating Inventory. ${ }^{89}$ The first is an accepting and non-attached attitude (ANA), which is the ability to exist in the present moment nonjudgmentally, without overanalyzing one's senses or thoughts. ${ }^{89}$ The second is awareness of senses while eating (ASE), which is simply tuning into one's physical senses, such as how the food smells, looks, or tastes, the texture of the food, or the sounds in one's environment while eating. ${ }^{89}$ The third is focused attention on eating (FAS), or limiting one's attention to the eating experience alone. ${ }^{89}$ The fourth is eating in response to awareness of fullness (ERF), or being cognizant of one's hunger and fullness cues in order to stop eating at the appropriate time. ${ }^{89}$ The fifth is awareness of eating triggers and motives (ATM), which means being aware of the reasons one is eating and recognizing when perhaps that desire to eat is rooted in a motive other than hunger, such as the desire for distraction or comfort. ${ }^{89}$ The sixth is a Non-Reactive Stance (NRS), which means approaching food in a decisive, intentional way rather than using food as a coping mechanism in reaction 
to a stressor. ${ }^{89}$ Lastly, interconnectedness (CON) is novel in the MEl and builds on the other six facets with the notion of connectedness to oneself, the food one is eating, and the people in one's environment. ${ }^{89}$ The newest operational definition for mindful eating serves to integrate all of these components into one working phrase that describes the nuanced facets of mindful eating. Each component of the MEI points toward the broader concepts of adaptive and maladaptive eating and serves to assess where an individual lies on the spectrum of eating patterns. ${ }^{89}$ However, as discussed previously, the concepts of adaptive and maladaptive eating may not be linear opposites. A 2019 study looked at the relationship between mindful eating, intuitive eating, and 'overeating regulation', which is the ability to self-regulate food intake and prevent overeating. ${ }^{13}$ These constructs are present in the practice-based theories of many nutrition professionals. ${ }^{90}$ While intuitive eating is not the same concept as mindful eating, much of the literature pertaining to eating behavior overlaps with regard to these two terms. ${ }^{16,91-93}$ Scales used to measure intuitive eating differ from those measuring mindful eating, but they analyze similar components of adaptive eating patterns. ${ }^{13,91}$ Intuitive eating subscales are inversely related to the three categories of maladaptive eating. Maladaptive eating is described as emotional, external, or restrained; intuitive eating subscales address the adaptive counterpart to these three types of maladaptive eating. ${ }^{13}$

Findings indicated that the ability to self-regulate overeating is tied strongly to the capacity for both intuitive eating and mindful eating, notably the ability to "eat for physical rather than emotional reasons." ${ }^{13}$ The authors noted that mindful 
eating was found to correlate with attuned eating, unrestrained eating, hunger awareness, and casual eating attitudes. ${ }^{13}$ However, they held in question whether mindful eating assessments need to be improved. They also considered the possibility that mindful eating may not be a strong factor in regulating eating behavior when compared to intuitive eating and overeating regulation. ${ }^{13}$

The research focus of Kerin et al. was more aligned with assessing "attuned" vs "disinhibited" behaviors. ${ }^{13}$ It categorized various subscales of eating behavior assessments in order to differentiate between adaptive vs maladaptive and attuned vs disinhibited behaviors in eating patterns. ${ }^{13}$ It is worth questioning based on this study whether "healthy" eating behaviors should be considered as those free of maladaptive traits, or if a broader approach should be taken. It may be that the combination of adaptive and maladaptive traits is the key, rather than the absence of maladaptive traits - similar to how gut health is distinguished by assessing the proportion of beneficial to pathogenic bacteria, rather than the complete absence of pathogenic bacteria.

The concepts related to homeostatic eating or "attuned eating" as it was termed, played into the notion that maybe these maladaptive and adaptive eating behaviors are not simply points on a spectrum of two extreme opposite behavior categories. It seems that rather than maladaptive and adaptive patterns existing exclusive to one another, there is a possibility that some maladaptive and adaptive eating behaviors can coexist. Based on the results of this study, it is apparent that aspects of attuned eating are found in both adaptive and maladaptive eating. This does not align with previous research implying that in order for a person's 
behaviors to be categorized as 'adaptive', they must contain virtually no aspects of maladaptive eating behavior. ${ }^{13}$

Moreover, it is valuable to recognize that in certain cases, behaviors tagged as 'maladaptive' might exist in less extreme forms in an eating pattern that is considered 'adaptive'. ${ }^{13}$ Future research should investigate whether certain eating styles labeled as maladaptive or adaptive should exist in exclusivity or in combination to produce desired health outcomes. The authors suggest that certain traits labeled under maladaptive eating may actually produce healthy behaviors when they exist in combination with the right adaptive traits. ${ }^{13}$ More research is certainly needed to clarify how these different components of eating behaviors may act synergistically or antagonistically with one another.

\section{Current Evidence for Mindful Eating Programs}

Mindful eating interventions have been administered in prior research with the goal of teaching participants adaptive eating mechanisms to replace their default maladaptive behaviors and establishing new connections in the brain with these mindful eating experiences. Taking the participant through lessons about eating behavior in response to stress and practical experiences that they can duplicate in the future has been hypothesized to help the participant gain selfefficacy using adaptive coping tools..$^{82,94-97}$ Theoretically, when food is not a part of the solution to the stressor, the participant understands how to recognize what they truly need and utilize a more appropriate coping mechanism. These programs are meant to teach individuals how to attend to their physiological and psychological needs when stressors arise. 
The key constructs discussed in the existing mindful eating interventions are hunger and satiety cues, sensory-specific satiety, body awareness, body wisdom, mindfulness, and intuitiveness. For example, Dr. Jean Kristeller's Mindfulness-Based Eating Awareness Training (MB-EAT) is an application of Kabat-Zinn's Mindfulness-Based Stress Reduction (MBSR) to the context of eating ${ }^{44,95}$ It teaches mindfulness principles along with specific eating awareness activities to enhance participants' experiential learning of the constructs. ${ }^{98}$ This program has been adapted for use with adolescent populations and termed MBEAT-A, with some limited evidence supporting its ability to increase physical activity and decrease fat intake among adolescents. ${ }^{98}$ Schaefer and Magnuson conclude that the interventions most helpful for improving attuned or mindful eating patterns include a nonjudgmental and nonrestrictive mindset, emphasizing neutrality toward food and body while prioritizing health outcomes over weightrelated outcomes. ${ }^{99}$

\section{Obesity}

Much of the existing literature involving mindfulness-based eating interventions pertains to obesity outcomes, as obesity is a growing public health concern and further evidence for behavioral health interventions is warranted. ${ }^{11,37,48,50,80,85,100-102}$ There is evidence to suggest that emotional eating mediates the relationship between depression and obesity, so emotion regulation is an important component to include in eating behavior interventions for obese populations. ${ }^{80}$ A 2015 literature review describes the status of mindfulness-based interventions (MBI) that focused on decreasing eating behaviors associated with 
obesity. ${ }^{37}$ Theories used to support the design of many MBIs include Escape Theory ${ }^{37,79,103}$ and Externality Theory. ${ }^{37,103}$ These theories help to highlight the different types of maladaptive eating and define behaviors that MBIs can attempt to improve. For example, using mindfulness practices in these interventions can help individuals to recognize difficult emotions or stressors and address them head-on rather than using food to avoid negative affect. This focus pertains to Escape Theory, which hypothesizes that eating for reasons other than hunger occurs due to a stressful event that drives a person to seek distraction from negative feelings. Escape Theory is supported by data indicating that locus of control and core self-evaluation play a mediating role between stress and eating patterns. ${ }^{79}$ Core self-evaluation is a term for one's conclusion about themselves based on awareness of their behaviors, ${ }^{104}$ and locus of control is the degree of one's conviction that they influence their own life outcomes rather than an external force. ${ }^{105}$

Another example is the use of Externality Theory to design a program that uses mindfulness to help individuals re-orient themselves toward homeostatic hunger cues rather than reacting to every urge to eat, such as the time of day ("It's lunchtime, so l'll eat even though l'm not hungry.") or the sight of food. ${ }^{37}$ Findings of this study indicate strong outcomes for using an MBI to decrease binge eating, as well as moderate outcomes for emotional and external eating. ${ }^{37}$ Dietary intake could not be assessed accurately because studies used a variety of dietary intake measurements. However, the overall conclusion is that implementing MBIs for the 
purpose of reducing obesity-related eating patterns is an evidence-based approach. ${ }^{37}$

A 2016 study utilized participants from the SHINE RCT cohort and measured the impact of mindful eating training and stress on the results of a weight loss program. ${ }^{101}$ The results of this study indicate that the use of mindfulness training alongside a weight loss program is helpful for decreasing reward-driven eating behaviors. ${ }^{101}$ While this does not provide proof of reward-driven eating as a mechanism for weight management, the authors strongly implicate the value of mindfulness for achieving desired health behaviors, specifically weight as it pertains to this study. ${ }^{101}$

\section{Eating Disorders}

MBIs have also been used in attempts to treat disordered eating patterns or clinical eating disorder symptoms..$^{93,97}$ Maladaptive eating can rapidly progress into a critical eating disorder requiring immediate treatment, so some scientists have worked to investigate mindful eating training as an additional line of defense to prevent the detrimental and sometimes fatal impacts of eating disorders. ${ }^{96,97} \mathrm{~A}$ case study on a female college student with anorexia nervosa found that the patient's BMI improved from 17.9 to 19.5 after a mindful eating intervention emphasizing attention to food taste, hunger cues, being present while eating, releasing control of thoughts, acceptance, and self-compassion/nonjudgment. ${ }^{96}$ In addition to restoring weight to within the "Normal" BMI category, this patient also doubled her prior daily energy intake after the program. ${ }^{96}$ 
A group intervention involving mindful eating practices was used in a sample of patients from an outpatient eating disorder clinic, demonstrating potential for using mindful eating interventions alongside traditional eating disorder treatment protocols, as evidenced by significant improvements in EAT-26 scores. ${ }^{97}$ Kristeller and Wolever's MB-EAT intervention was studied in the context of binge eating disorder, finding that MB-EAT was able to reduce frequency of binges and participants' self-efficacy in terms of feeling in control of their eating patterns. ${ }^{95}$ This intervention was also studied in 2018 to evaluate outcomes for both obesity and binge eating disorder, concluding that mindful eating training promotes "spiritual engagement" and this increased sense of spirituality and wisdom contributes to better regulation of eating behaviors. ${ }^{106}$

\section{Research Gaps}

There is a significant gap in data regarding the impact of mindful eating scores on positive or negative health outcomes, such as increased self-regulation or disordered eating behaviors. Many studies have examined the relationship of intuitive eating to both eating behavior and metabolic health outcomes since this topic has gained more traction in healthcare and academia. ${ }^{16,91-93}$ However, there is less evidence for the use of mindful eating interventions for improved health outcomes. ${ }^{85}$ There is also a lack of research exploring MB-EAT in the college student population; to date, it has only been used in adult and adolescent groups, but not in young adults ages 18-24.

There are also limitations to the accuracy and completeness of food intake and behavior assessments that rely on participants to self-report data, making it 
difficult to know whether the significant evidence for mindful eating is truly accurate. Therefore, there is insufficient quantity and quality of evidence to strongly tie improved mindful eating scores to specific health outcomes that would justify a notable shift in the design of patient care plans. More evidence for the relationship between both mindful eating and physiological stress, as well as evidence for the mindfulness-based eating intervention as an effective treatment modality, is necessary before practitioners can confidently use these interventions with the knowledge that they will not waste time and money for both the patient and the healthcare system. Beyond the healthcare system, there is a significant need for more research with mindful eating interventions in groups of college students, as there is currently a myriad of studies on general stress in college students, but limited information about the combination of stress and eating behavior outcomes in this population.

Furthermore, much of the research pertaining to mindful eating lacks statistical weight due to the use of measurements that are not validated, a sample size less than 25 , or insufficient statistical power. Many studies showed no calculation of statistical power at all, indicating a need for more statistical rigor in the realm of mindful eating research. Future research can focus on obtaining as much objective data as possible with regard to physiological stress markers and mindful eating outcomes. Justification for future research in college students exists, and in the coming years it will be necessary to repeat and refine current pilot studies in order to impact the resources available to young adults struggling 
with chronic stress, functional gastrointestinal disorders, and maladaptive eating behaviors. 


\section{Participants}

\section{Chapter 3: Methodology}

Participants were students attending Winthrop University during the 20202021 academic year, in the midst of the COVID-19 pandemic. Since the majority of students who did not complete the entire survey stopped at $77 \%$ completion, only those who completed $\geq 77 \%$ of the survey were included in data analysis.

\section{Procedure}

This project was approved by the Winthrop University Institutional Review Board as exempt from full IRB review. A survey was distributed to the entire student body three times per week between the dates of November 30, 2020 and January 11, 2021, with the exception of winter break. Informed consent was gathered in the first question using a yes/no format. A debriefing statement was displayed upon completion of the study with the researchers' contact information. Participants were provided a link to a separate survey which allowed them to enter to win one of two $\$ 25$ Amazon gift cards as an incentive for completion of the survey.

\section{Instrumentation}

The first portion of the survey collected information on student demographics (see Appendix A). In addition, students were asked about the use of common behaviors associated with stress relief among college students: smoking, alcohol intake, and recreational drug use. The second portion of the survey instrument included a combination of validated assessment tools (Perceived Stress Scale ${ }^{9}$, Mindfulness Attention Awareness Scale ${ }^{43}$ ) and derived mindful eating questions termed the "Mindful Eating Self-Assessment." All survey 
components can be found in Appendix A. The Perceived Stress Scale (PSS) measures a person's perceived level of overall life stress. ${ }^{9}$ Scores are the total of all 10 responses, and higher scores indicate a greater level of stress. The initial test-retest correlation for the PSS is $0.85 .{ }^{9}$ The Mindfulness Attention Awareness Scale (MAAS) measures overall mindfulness patterns using a 15-item, 6-point Likert scale. ${ }^{43}$ Scores are the average of all 15 responses, and higher scores indicate a greater degree of mindfulness. Cronbach's alpha for the MAAS is $\alpha=$ 0.89 , reflecting good internal reliability. ${ }^{43,107}$ The Mindful Eating Self-Assessment (MESA) includes questions similar to general mindfulness questions, but applied to the mealtime experience. Scores are the total of all 6 responses, and higher scores indicate a greater degree of mindful eating. Lastly, gastrointestinal history and symptoms were assessed, including a Bristol Stool Chart rating. ${ }^{108}$

\section{Data Analysis}

Data was analyzed using IBM SPSS Statistics version 27.0 for Macintosh (IBM Corp., Armonk, New York). Descriptive statistics and Pearson correlations were used to draw conclusions about survey data. Scatter plots were produced using GraphPad Prism version 9.0.2 for Macintosh (GraphPad Software, San Diego, California). Statistical significance was set at $p<0.05$. 


\section{Chapter 4: Results}

\section{Demographics}

Out of the 131 students who submitted responses, 109 completed the entire survey. 129 participants were eligible for analysis after eliminating inadequate survey responses (<77\%). Ages ranged from 18 to 49 years, with a mean age of $21.21+/-4.64$ (mean +/- SEM). The majority of participants were female (see Table 2). The majority of participants were students in the College of Arts and Sciences (see Table 2), and the largest groups by class were juniors and seniors (see Table 2). The majority of participants had never been diagnosed with an eating disorder, and among those with an eating disorder history, anorexia nervosa was the predominant diagnosis (see Table 2). The majority of participants practiced mindfulness once per week or less (see Table 3).

Table 2. Frequency data for demographic information: sex, major (by academic college), year of education, and history of eating disorder diagnosis.

\begin{tabular}{|c|c|c|}
\hline & $\mathrm{N}$ & $\%$ \\
\hline \multicolumn{3}{|l|}{ Sex* } \\
\hline Female & 96 & 88.1 \\
\hline Male & 10 & 9.2 \\
\hline Prefer not to say & 3 & 2.8 \\
\hline Total & 109 & 100.0 \\
\hline \multicolumn{3}{|l|}{ Academic College* } \\
\hline Arts \& Sciences & 62 & 57.4 \\
\hline Business Admin. & 8 & 7.4 \\
\hline Education & 22 & 20.4 \\
\hline Visual/Performing Arts & 14 & 13.0 \\
\hline University College & 2 & 1.9 \\
\hline Total & 108 & 100.0 \\
\hline \multicolumn{3}{|l|}{ Year of Education* } \\
\hline Freshman & 21 & 19.3 \\
\hline Sophomore & 11 & 10.1 \\
\hline Junior & 27 & 24.8 \\
\hline Senior & 33 & 30.3 \\
\hline Graduate Student & 17 & 15.6 \\
\hline
\end{tabular}


Total

Eating Disorder History**

None

Anorexia Nervosa

Bulimia Nervosa

Binge Eating Disorder

Other

Prefer not to say

Total

\begin{tabular}{cc}
\hline 109 & 100.0 \\
& \\
91 & 83.5 \\
\hline 6 & 5.5 \\
\hline 2 & 1.8 \\
\hline 3 & 2.8 \\
\hline 6 & 5.5 \\
\hline 1 & 0.9 \\
\hline 109 & 100.0 \\
\hline
\end{tabular}

${ }^{*}$ Data was missing from 21 participants.

${ }^{* *}$ Data was missing from 20 participants.

Table 3. Frequency of mindfulness practices (times per week).

\begin{tabular}{lcc}
\hline & $\mathrm{N}^{*}$ & $\%$ \\
\hline$<1$ & 34 & 34.0 \\
\cline { 2 - 3 } 1 & 29 & 29.0 \\
\cline { 2 - 3 } 2 & 17 & 17.0 \\
3 & 12 & 12.0 \\
4 & 5 & 5.0 \\
$5+$ & 3 & 3.0 \\
\cline { 2 - 3 } Total & 100 & 100.0 \\
\cline { 2 - 3 }
\end{tabular}

${ }^{*}$ Data was missing from 29 participants.

Gastrointestinal parameters were obtained for history of IBS and IBD diagnosis as well as symptom patterns (see Table 4). The majority of participants who responded to the GI portion of the survey were never diagnosed with IBS or IBD, but individual symptoms were more common (see Table 4). All participants reported their smoking, alcohol, and drug use behaviors (see Table 5). For outcomes of the PSS, MAAS, and MESA, see Table 6.

Table 4. Frequency data for gastrointestinal parameters.

IBS Diagnosis

$\begin{array}{lcc}\text { No } & 95 & 87.2 \\ \text { Yes } & 14 & 12.8 \\ \text { Total }^{*} & 109 & 100.0\end{array}$

IBD Diagnosis

$\begin{array}{lcc}\text { No } & 108 & 99.1 \\ \text { Yes } & 1 & 0.9\end{array}$


Total $^{*}$

Pain Frequency

Never

1-2 times per month

\begin{tabular}{cc}
20 & 18.3 \\
\hline 42 & 38.5 \\
\hline 36 & 33.0 \\
\hline 11 & 10.1 \\
\hline 109 & 100.0
\end{tabular}

Pain Severity

$$
\begin{aligned}
& 1+\text { times per week } \\
& 1+\text { times per day }^{*} \\
& \text { Total }^{*}
\end{aligned}
$$

0

1

2

3

4

5

Total $^{* *}$

\begin{tabular}{cc}
2 & 2.4 \\
\hline 8 & 9.5 \\
\hline 43 & 51.2 \\
\hline 26 & 31.0 \\
\hline 3 & 3.6 \\
\hline 2 & 2.4 \\
\hline 84 & 100.0
\end{tabular}

Liquid Stool

Never

1-2 times per month or less

$1+$ times per week

$1+$ times per day

Total $^{* * *}$

Stool Frequency

Less than daily

1-2 stools per day

3-4 stools per day

$5+$ stools per day

Total $^{\star \star *}$

Bristol Stool Chart Rating

1

2

3

4

5

6

7

Total $^{\star \star * *}$

\begin{tabular}{cc}
29 & 28.4 \\
\hline 56 & 54.9 \\
\hline 16 & 15.7 \\
\hline 1 & 1.0 \\
\hline 102 & 100.0
\end{tabular}

\begin{tabular}{cc}
18 & 17.6 \\
\hline 75 & 73.5 \\
\hline 8 & 7.8 \\
\hline 1 & 1.0 \\
\hline 102 & 100.0
\end{tabular}

\begin{tabular}{cc}
3 & 3.0 \\
\hline 17 & 16.8 \\
\hline 34 & 33.7 \\
\hline 28 & 27.7 \\
\hline 15 & 14.9 \\
\hline 4 & 4.0 \\
\hline 0 & 0.0 \\
\hline 101 & 100.0
\end{tabular}

${ }^{*}$ Data was missing for 20 participants.

${ }^{* *}$ Data was missing for 45 participants.

***Data was missing for 27 participants.

${ }^{* * * *}$ Data was missing for 28 participants. 
Table 5. Frequency data for smoking, alcohol intake, and drug use.

\begin{tabular}{|c|c|c|}
\hline & $\mathrm{N}^{*}$ & $\%$ \\
\hline \multicolumn{3}{|l|}{ Smokes Currently } \\
\hline No & 101 & 92.7 \\
\hline Yes & 8 & 7.3 \\
\hline Total & 109 & 100.0 \\
\hline \multicolumn{3}{|l|}{ Smoking Frequency } \\
\hline Never & 101 & 92.7 \\
\hline 1-2 times per month or less & 1 & 0.9 \\
\hline 1 or more times per week & 3 & 2.8 \\
\hline 1 or more times per day & 4 & 3.7 \\
\hline Total & 109 & 100.0 \\
\hline \multicolumn{3}{|l|}{ Alcohol intake } \\
\hline No & 50 & 45.9 \\
\hline Yes & 59 & 54.1 \\
\hline Total & 109 & 100.0 \\
\hline \multicolumn{3}{|l|}{ Alcohol Frequency } \\
\hline Never & 50 & 45.9 \\
\hline $1-2$ times per month or less & 39 & 35.8 \\
\hline 1 or more times per week & 19 & 17.4 \\
\hline 1 or more times per day & 1 & 0.9 \\
\hline Total & 109 & 100.0 \\
\hline \multicolumn{3}{|l|}{ Drug Use ${ }^{* *}$} \\
\hline No & 72 & 66.1 \\
\hline Yes & 37 & 33.9 \\
\hline Total & 109 & 100.0 \\
\hline \multicolumn{3}{|l|}{ Drug Frequency** } \\
\hline Never & 72 & 66.1 \\
\hline $1-2$ times per month or less & 14 & 12.8 \\
\hline 1 or more times per week & 18 & 16.5 \\
\hline 1 or more times per day & 5 & 4.6 \\
\hline Total & 109 & 100.0 \\
\hline
\end{tabular}

${ }^{*}$ Data was missing for 20 participants.

${ }^{* *}$ There was an error in the skip logic on this survey question. The survey was supposed to skip following question about frequency if participant answered "no," but it allowed participants to select "Never" in frequency question after they may have selected "Yes" for drug use (See Appendix A). 
Table 6. Descriptive statistics scores on PSS, MAAS, and MESA.

\begin{tabular}{|c|c|c|c|c|c|}
\hline & $\mathrm{N}$ & Min & Max & Mean & Std. Deviation \\
\hline PSS (Total)* & 109 & 9.00 & 38.00 & 22.76 & 6.86 \\
\hline MAAS (Average)* & 109 & 1.13 & 5.60 & 3.33 & 0.91 \\
\hline MESA (Total) $)^{* \star}$ & 108 & 3.00 & 18.00 & 11.47 & 3.86 \\
\hline
\end{tabular}

${ }^{*}$ Data was missing for 20 participants.

${ }^{* *}$ Data was missing for 21 participants.

\section{Relationships}

No statistically significant relationships were found between alcohol intake or drug use and scores for PSS, MAAS, or mindful eating. Smoking was found to be negatively correlated with PSS scores $(r=-0.191, p=0.047, N=109)$. Gastrointestinal parameters tended to be positively correlated with stress levels. PSS scores were associated with increased pain frequency $(p=0.001)$ and trended towards significance $(p=0.075)$ with presence of liquid stools. There was a statistically significant, moderately negative correlation between total PSS scores (PSSTotal) and averaged MAAS scores (MAASAverage) (see Figure 5). There was also a statistically significant, moderately negative correlation between total PSS scores (PSSTotal) and total Mindful Eating Self-Assessment scores (ME Sum) (see Figure 6). 


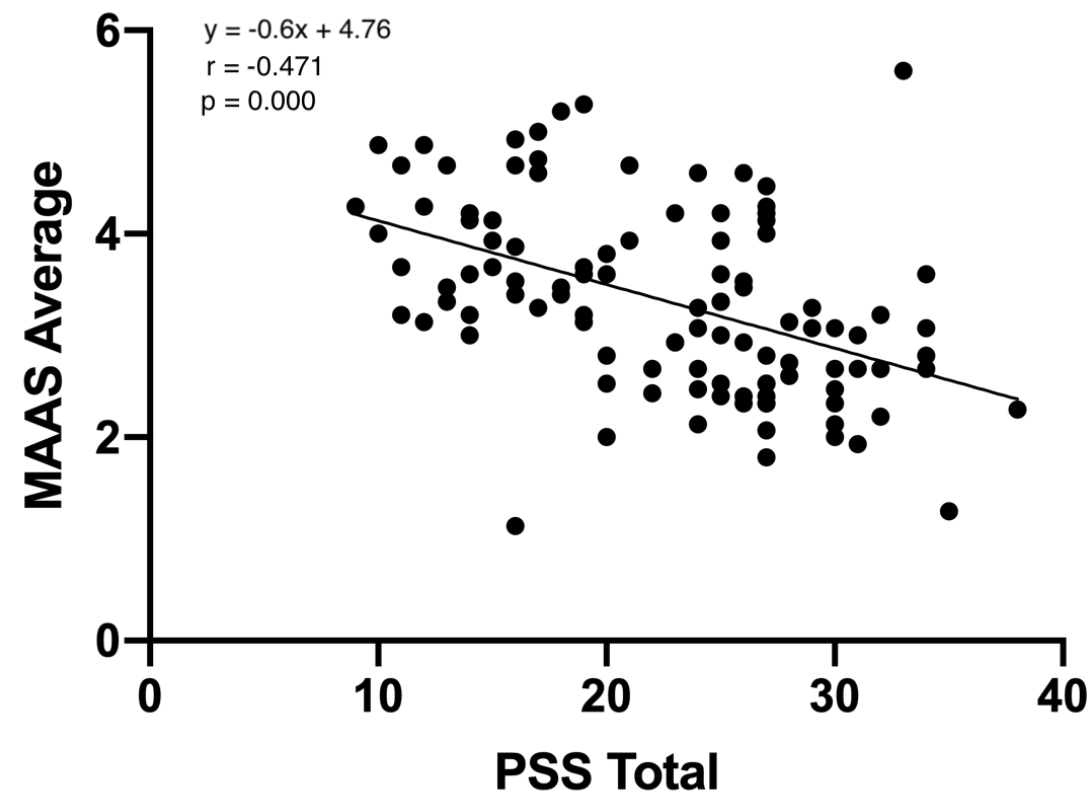

Figure 5. Scatter plot and line of best fit for Pearson correlation between PSS score and MAAS score (MAAS Average).

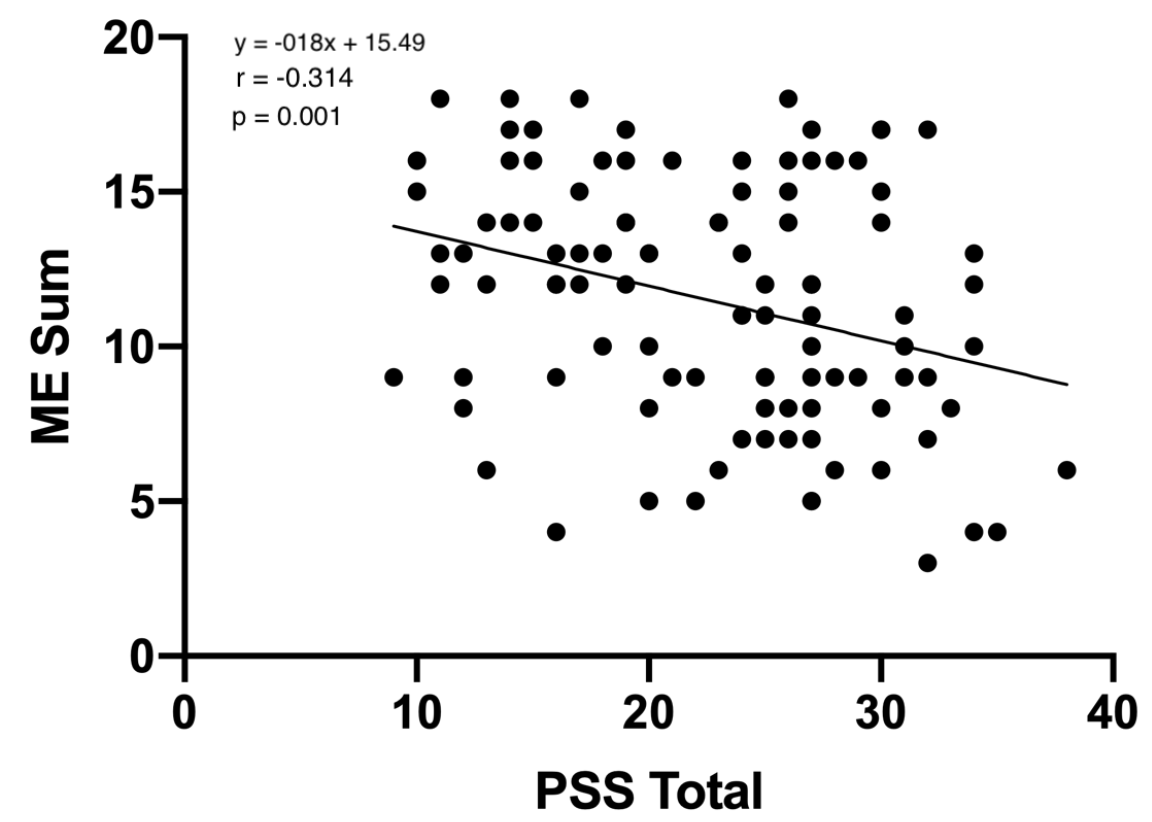

Figure 6. Scatter plot and line of best fit for Pearson correlation between PSS score and MESA score (ME Sum). 


\section{Chapter 5: Discussion}

This study aimed to assess 1) the relationship between students' perceived stress and mindfulness, 2) the relationship between students' perceived stress and mindful eating, 3) the role that $\mathrm{Gl}$ parameters play in participants' stress, mindfulness, and mindful eating patterns, and 4) the role that alternate coping mechanisms such as smoking, alcohol intake, and drug use play in the same three measurements. The results of this study indicate an inverse relationship between students' level of perceived stress and their degree of mindfulness. Additionally, an inverse relationship was indicated between students' perceived stress and mindful eating patterns. The observation that increased stress levels correlate with lower mindfulness and mindful eating in this population suggests a need for future research that examines this relationship in more depth. The results of this study also warrant the exploration of mindful eating program outcomes in the college student population.

Smoking, alcohol intake, and drug use were assessed to control for other potential coping behaviors that may have impacted stress levels and mindfulness habits. The goal was to determine whether any of these parameters decreased mindful eating behaviors. PSS scores were correlated with a decrease in smoking frequency, indicating that stress levels are higher in those that smoke less frequently. There was a statistically significant correlation between smoking and PSS scores, and PSS scores were insignificantly correlated with drug use and alcohol intake. 
PSS scores in this student population $(M=22.76)$ are similar to another study reporting an average score of 29.86 for students who completed an MBSR program. ${ }^{43}$ A study analyzing perceived stress among Saudi Arabian students completing virtual coursework during the COVID-19 pandemic reported averages of 22.75 for female students and 20.27 for male students, which demonstrates a significantly greater degree of perceived stress in females within that student sample $(p=0.03) .{ }^{109}$ It is noteworthy that the majority of students fell within the "moderate stress" category (PSS score between 14 and 26), indicating that while this virtual learning environment did not cause an acute degree of perceived stress in many students, the majority experienced a manageable but likely persistent form of stress, which could have implications for health and academic performance in the future. ${ }^{109}$

The impact of isolation and virtual environments on perceived stress is certainly worth examining in more detail, especially in adolescents who will soon enter the college student population. Another important avenue of investigation involves children who were in elementary or middle school during the COVID-19 pandemic. A study on parent and child stress during the initial COVID-19 lockdown found that children ages $10-13$ had an average PSS score of 1.13 , indicating a lower level of stress compared to college students. ${ }^{110}$ This is logical given the increased degree of responsibility that college students needed to manage while adjusting to a virtual environment, but it may be prudent to observe stress among younger children longitudinally to determine the long-term effects of the pandemic on academic stress. While universities can utilize research on stress in college 
students to improve their available resources, it will be crucial in the coming years to identify novel ways that stress manifests itself in students who were affected by the pandemic at younger ages so that universities can be adequately prepared to support these students. It would also be worth conducting mindful eating assessments in students who lived through the COVID-19 pandemic to identify nutrition and eating-related needs in this population.

MAAS scores $(M=3.33)$ were lower than another report of MAAS scores among college students, with Brown and Ryan's original validation study reporting a mean score of 3.85 for a subgroup of psychology students. ${ }^{43}$ A 2014 study reported a higher mean in a group of Spanish students $(M=3.57)$ than that of Winthrop students, but lower than Brown and Ryan's student sample. ${ }^{111}$ The impact of COVID-19 has also been explored for MAAS scores, with one study reporting an average score of 3.5 in female university students and 3.9 in male students after the first COVID-19 lockdown period in Italy. ${ }^{112}$

Previous research does support the negative correlation between stress and mindfulness that was found in this study. ${ }^{10,33,53,84,85}$ Mason et al. found that when stress levels were increased by administering naltrexone to a sample of women in a mindfulness-based intervention, thereby increasing cortisol, their cortisol levels were significantly correlated with increased adaptive eating behaviors, and inversely correlated with mindful eating behaviors. ${ }^{85}$ While this study did not utilize cortisol to measure stress, another author noted that PSS scores tended to be higher in groups of participants that showed a significant correlation between stress and emotional eating..$^{84}$ Those with lower stress levels 
to begin with did not show as dramatic of a correlation between stress and emotional eating. ${ }^{84}$

While the present study did not find a significant correlation between overall gastrointestinal parameters and mindfulness or stress, previous research has observed an association between stress and diarrhea-type symptoms, such as liquid stools and abdominal pain. A 2019 study on the impact of life stressors on diarrhea symptoms supports the finding that increased diarrhea-like symptoms are associated with a greater degree of stress. ${ }^{113}$ However, since the experience of frequent diarrhea in itself can also act as a life stressor, more research is needed to confirm whether other life stress or diarrhea-related stress is most commonly the original trigger for the cyclic relationship between GI symptoms and stress. The limitations of research may not allow for a true understanding of the root causes in patients with diarrhea or other IBS subtypes, as it would require following patients before the onset of symptoms, and the rigorous measurements required to monitor life stress and GI symptoms may become a contributor to participants' life stress, obstructing the end goal.

The role of maladaptive coping mechanisms other than eating (smoking, alcohol intake, and drug use) were inconclusive in this study. No significant relationships were found between any of the three alternative coping methods and stress or mindful eating, which is logical given that these coping mechanisms are likely to alter an individual's perceived life stress. There is a lack of publications examining these alternate coping methods with respect to appetite and eating behavior, but nicotine is thought to have an appetite-suppressing effect, which 
could impact mindful eating behaviors. ${ }^{114}$ There is also little research on alcohol's role in eating behavior, but it is commonly observed that alcohol gradually decreases one's attention to detail and decision-making skills. Recreational drug use can relieve stress by diverting the mind from the present moment, but effects of drug use vary widely depending on the type of substance. Research on cannabis use in relationship with facets of mindfulness has recently found a significant negative correlation between cannabis use and scores for both non-judgment and awareness, and there is evidence to suggest that mindfulness-based interventions can lower prevalence of cannabis use. ${ }^{77,78}$ In contrast with the literature that suggests mindfulness is negatively correlated with cannabis use, there are healthcare settings such as post-chemotherapy where cannabis is used to increase mindfulness by allowing the patient to exist in the present moment without experiencing intense pain. ${ }^{115}$ More research is needed to understand in what contexts drug use can increase or decrease mindful eating behaviors.

\section{Strengths \& Limitations}

Strengths

The key strength of this study was the use of validated assessments in the survey. The PSS and MAAS have both been thoroughly validated in prior research, which supports the significance of this study's findings. Additionally, the length of the survey was manageable for the majority of participants, so very few survey responses were removed due to inadequate completion.

\section{Limitations}


Limitations of this study include the lack of biochemical analysis, lack of diversity-related demographic information, and lack of a validated mindful eating assessment. The initial study design included collection of urinary cortisol for analysis, but due to the COVID-19 pandemic, collecting biospecimens was not feasible. Future studies in this population can restrict the inclusion criteria to college students ages $18-24$ to obtain data that is specific to the traditional college student profile, and other demographic factors such as pregnancy, smoking, alcohol intake, and drug use can be factored out to control for these factors more strictly. Future studies can also investigate discrepancies across racial/ethnic groups and examine areas for improving diverse access to information about mindfulness and mindful eating.

The lack of a validated mindful eating questionnaire in lieu of the Mindful Eating Self-Assessment leaves room for improvement upon this study. The Mindful Eating Questionnaire (MEQ), Eating Attitudes Test (EAT), the Three-Factor Eating Questionnaire (TFEQ), or the Dutch Eating Behavior Questionnaire (DEBQ) are all validated substitutes that could have been incorporated into the survey for this study. Part of the reasoning for keeping the existing questions was to decrease resistance against completing the entire survey. While analyzing the data, we noticed that participants who stopped taking the survey tended to stop at the complex questions corresponding to the PSS and MAAS, so adding an additional set of questions would have increased the time to complete the survey and decreased the sample size. The results of this study still benefit the target population by demonstrating a need for more stress management and mindfulness 
training for students, and mindful eating should be investigated with greater rigor in future studies with college students.

Lastly, the survey flow is a potential limitation of this research. Gastrointestinal parameters were not found to be strongly correlated with the mindful eating, so it could have been removed from the survey for a more simplified user experience. Perhaps a separate study identifying relationships between GI parameters and mindful eating is worth performing, but for this study the $\mathrm{Gl}$ component did not add significant value to the results. This edit may have improved completion of the survey, since several individuals stopped answering questions at the beginning of the $\mathrm{Gl}$ questions.

\section{Future Research}

Future research could further investigate the relationship between stress levels and mindful eating behaviors by incorporating a biochemical analysis of cortisol once it is safe to do so. Methodology could also be adjusted to collect data from cluster samples of majors or academic college categories to determine how one's field of study influences perceived stress and mindful eating.

Additionally, future research on stress and mindful eating should use the most advanced validated tools to ensure results are thorough. The previous mindful eating assessment tools (MEQ, DBEQ, and TFEQ) did not encompass all aspects of mindful eating, nor did the existing research specify an objective definition for 'mindful eating' until Peitz et al. developed the MEl. ${ }^{89}$ This tool is new, so additional validation studies are needed to confirm that this tool is an effective measurement across varying demographics and population sizes, but it offers 
promising initial validation results. ${ }^{89}$ Use of the MEI in future studies assessing mindful eating through cross-sectional designs or intervention trials would be prudent, as this tool would have been a great asset for this study's results regarding mindful eating. Pending additional validation, using it as an assessment for future MBls would add to the evidence for MBIs improving mindful eating outcomes. The nature of this tool also allows for more inference of any mechanisms by which mindful eating achieves positive behavioral and physical outcomes, so it may prove to be extremely helpful for pushing the boundaries of this area of research based on the authors' reasoning for its design. ${ }^{89}$

Future studies on mindful eating in college students can examine specific interventions, such as MB-EAT or other mindfulness-based eating interventions. See Appendix B for a mindful eating program outline that was developed based on MB-EAT for adolescents (MB-EAT-A) ${ }^{98}$ prior to the COVID-19 pandemic.

\section{Conclusion}

The results of this study indicate a significant negative correlation between perceived stress and overall mindfulness among college students. This study also found a significant negative correlation between perceived stress and mindful eating, but future research is needed with validated mindful eating assessment tools in order to confirm the significance of this finding. Gastrointestinal parameters related to diarrhea were positively associated with stress levels, but all other GI parameters did not show a significant relationship to stress levels or mindful eating. Smoking was found to be negatively associated with mindfulness. Drug use and alcohol intake were not found to be strongly associated with either stress levels or 
mindful eating, and it is difficult to make conclusions about the influence these factors on stress and mindful eating due to interpersonal differences in response to substance use, as well as conflicting research specifically regarding cannabis use and mindfulness levels. Future research can more thoroughly investigate the connection between life stressors and mindful eating behaviors, perhaps looking more closely at the subcategories of maladaptive eating behaviors and their relationship to stress. Additionally, more research is required to fully comprehend the impact of alternative coping mechanisms such as nicotine, alcohol, and drugs on the stress response and engagement in maladaptive eating behaviors. 


\section{Appendix A: Qualtrics Survey}

\section{Informed Consent}

\section{INFORMED CONSENT FORM ONLINE SURVEY}

You are invited to take part in a research study whose purpose is to determine the impact of mindful eating training on perceived stress levels and perceived mindful eating behaviors. This study is open to Winthrop students between the ages of 18-24. Your decision to take part in this study is voluntary. You are free to choose whether or not you will take part in the study. Even if you decide to participate now, you may change your mind and stop at any time. You may choose not to answer an individual question, or you may skip any section of the survey. Simply click "Next" at the bottom of the survey page to move to the next question.

Your participation will last about 10-15 minutes. You will be completing an anonymous online survey (26 questions, 10-15 minutes).

This project is deemed as no more than minimal risk. The research team does not foresee or anticipate any risk greater than that encountered in your routine daily activities.

While you may not receive any direct benefit for participating, we hope that this study will provide you with an increased ability to use mindful eating practices and recognize stress in the body. If you are interested in learning the results of the study, you may contact the researchers after (date TBD).

Your cost to participate in the study is the time that you will dedicate to this activity. 
Researchers will make no attempt to link your survey responses to you. We may publish the results of this study, but will not include any information that would identify you.

If you have questions about this research study, you may contact me via email - Emily Garrett (garrette3@mailbox.winthrop.edu).

You may also contact me through my faculty advisor, Dr. Jessie Hoffman, at hoffmanjb@winthrop.edu, Dalton 306A, or by phone at (803) 323-3961.

You may also contact:

Grants and Sponsored Research Development Winthrop University

Rock Hill, SC 29733

Telephone: 803-323-2460

By clicking on "Yes, I agree to participate," you agree that you have read this informed consent agreement, you understand what is involved, and you are consenting to participate in this research study,

If you do not wish to participate, select "No, I do not wish to participate" to exit the survey.

Yes, I agree to participate.

No, I do not wish to participate.

\section{Mindful Eating Survey}

What is your age? (Please enter numbers only.)

What is your sex?
Male
Female
Prefer not to say 
What is your major?

What is your year of education?

Freshman

Sophomore

O Junior

Senior

Graduate Student

On average, how many times per week do you use mindfulness techniques (meditation, mindful movement, deep breathing, body scan, yoga practice, etc)?

O (less than once per week)

O 1

$\mathrm{O}_{2}$

$\mathrm{O} 3$

$\mathrm{O}_{4}$

○ 5

5+

Have you ever been diagnosed with an eating disorder? If yes, please specify.

$\mathrm{O}$ Yes

No

What was your eating disorder diagnosis?

Anorexia Nervosa

Bulimia Nervosa

Binge Eating Disorder 

Other
Prefer not to say

Do you currently smoke?
$\mathrm{O}$ Yes
O No

On average, how often do you smoke?
Never
1-2 times per month or less
O 1 or more times per week
O 1 or more times per day

When you smoke, what is typically your social setting?
Socially, with a large group
O Socially, with 1-3 friends
O Alone

Do you drink alcohol?
$\mathrm{O}$ Yes
O No

On average, how often do you drink alcohol?
O Never
O 1-2 times per month or less
O 1 or more drinks per week
O 1 or more drinks per day 
When drinking alcohol, what is typically your social setting?

O Socially, with a large group

O Socially, with 1-3 friends

O Alone

Have you ever used recreational drugs?

$\mathrm{O}$ Yes

O No

How often do you use recreational drugs?

O Never

1-2 times per month or less

O 1 or more times per week

O 1 or more times per day

When you use recreational drugs, what is typically your social setting?

Socially, with a large group

Socially, with 1-3 friends

O Alone

The questions in this scale ask you about your feelings and thoughts during the last month. In each case, select how often you felt or thought a certain way.

$$
0=\text { Never } \quad \begin{array}{cccc}
1=\text { Almost } & 2= & 3=\text { Fairly } & 4=\text { Very } \\
\text { Never } & \text { Sometimes } & \text { Often } & \text { Often }
\end{array}
$$

1. In the last month, how often have you been upset because of something that happened unexpectedly?

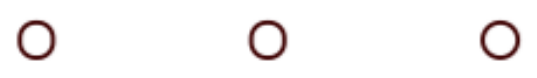


$1=$ Almost

Never

2. In the last month, how often have you felt that you were unable to control the important things in your life?

3. In the last month, how often have you felt nervous and "stressed"?

4. In the last month, how often have you felt confident about your ability to handle your personal problems?

5. In the last month, how often have you felt that things were going your way?

6. In the last month, how often have you found that you could not cope with all the things you had to do?

7. In the last month, how often have you been able to control irritations in your life?

8. In the last month, how often have you felt that you were on top of things?

9. In the last month, how often have you been angered because of things that were outside of your control?

10. In the last month, how often have you felt difficulties were piling up so high that you could not overcome them?

$\mathrm{O}$

$\mathrm{O}$

O $\quad 0$

O $\quad 0$

O $\quad 0$

O $\quad 0$

O $\quad 0$

$\mathrm{O}$

$\mathrm{O}$
$\mathrm{O}$
$\mathrm{O}$
O
$\mathrm{O}$
$\mathrm{O}$

O

$\mathrm{O}$

$\mathrm{O}$

O

$\mathrm{O}$

0

O

$\mathrm{O}$

$\mathrm{O}$

$\mathrm{O}$

$\mathrm{O}$

$\mathrm{O}$

$\mathrm{O}$

$\bigcirc$

$\mathrm{O}$

$\mathrm{O}$

O

$\mathrm{O}$

$\mathrm{O}$

$\mathrm{O}$

$\mathrm{O}$ 
Instructions: Below is a collection of statements about your everyday experience. Using the 1-6 scale below, please indicate how frequently or infrequently you currently have each experience. Please answer according to what really reflects your experience rather than what you think your experience should be. Please treat each item separately from every other item.

\begin{tabular}{|c|c|c|c|c|}
\hline $\begin{array}{c}1= \\
\text { Almost }\end{array}$ & 2 = Very & $\begin{array}{c}3= \\
\text { Somewhat }\end{array}$ & $\begin{array}{c}4= \\
\text { Somewhat }\end{array}$ & 5 = Very \\
\hline Always & Frequenty & Frequently & infrequently & Infrequently \\
\hline
\end{tabular}

1. I could be experiencing some emotion and not be conscious of it until some time later.

2. I break or spill things because of carelessness, not paying attention, or thinking of something else.

3. I find it difficult to stay focused on what's happening in the present.

4. I tend to walk quickly to get where I'm going without paying attention to what I experience along the way.

5. I tend not to notice feelings of physical tension or discomfort until they really grab my attention.

6. I forget a person's name almost as soon as I've been told it for the first time.

7. It seems I am "running on automatic," without much awareness of what I'm doing. I rush<smiles>O</smiles>

O

O

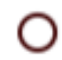

O $\mathrm{O}$

O

O

O through activities without being really attentive to them. 
8. I rush through activities without being really attentive to them.

9. I get so focused on the goal I want to achieve that I lose touch with what I'm doing right now to get there.

10. I do jobs or tasks automatically, without being aware of what I'm doing.

11. I find myself listening to someone with one ear, doing something else at the same time.

12. I drive places on 'automatic pilot' and then wonder why I went there.

13. I find myself preoccupied with the future or the past.

14. I find myself doing things without paying attention.

15. I snack without being aware that I'm eating.
$1=$

Almost

Always

2 = Very

$3=$

$4=$

Somewhat Somewhat

Frequenty
Frequently infr

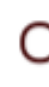

O

O

O

O $\mathrm{O}$

O

O

O

O

O

O

O

O

O

O

O

O

O $\mathrm{O}$

$\mathrm{O}$

O

$\mathrm{O}$

O

O

O

O

○

O

O

$\mathrm{O} \quad \mathrm{O}$

O

O

O

Please select the most accurate frequency for the statements below.

Never
$\begin{aligned} & \text { When I eat, I make } \\ & \text { sure there are minimal } \\ & \text { distractions in my } \\ & \text { environment }\end{aligned}$




\begin{tabular}{|c|c|c|c|c|}
\hline & Never & Rarely & $\begin{array}{l}\text { About half of } \\
\text { the time }\end{array}$ & $\begin{array}{l}\text { Most of the } \\
\text { time }\end{array}$ \\
\hline $\begin{array}{l}\text { When I eat a meal, I sit } \\
\text { down at a space set } \\
\text { up specifically for } \\
\text { mealtime. }\end{array}$ & 0 & 0 & 0 & $\mathrm{O}$ \\
\hline $\begin{array}{l}\text { I eat meals with other } \\
\text { people }\end{array}$ & $\Omega$ & & 0 & $\bigcirc$ \\
\hline $\begin{array}{l}\text { When eating, I pay } \\
\text { attention to how the } \\
\text { food tastes. }\end{array}$ & 0 & & 0 & 0 \\
\hline $\begin{array}{l}\text { When eating, I pay } \\
\text { attention to how my } \\
\text { body feels. }\end{array}$ & 0 & 0 & 0 & 0 \\
\hline $\begin{array}{l}\text { After a meal, I feel full } \\
\text { but still can't stop } \\
\text { thinking about food. }\end{array}$ & 0 & 0 & 0 & $\mathrm{O}$ \\
\hline
\end{tabular}

Have you ever been diagnosed with Irritable Bowel Syndrome (IBS)?

Yes

No

Have you ever been diagnosed with Irritable Bowel Disease (IBD - Crohn's or Ulcerative Colitis)?

$\mathrm{O}$ Yes

No

On average, how often do you experience abdominal pain or discomfort?

Never

1-2 times per month or less

O 1 or more times per week

O or more times per day

Please rate the severity of your abdominal pain/discomfort on a scale of 0-5. 

$\mathrm{O} 0$
○ 1
$\mathrm{O} 2$
$\mathrm{O} 3$
O 4
O 5

On average, how often do you experience liquid stools?
O Never
1-2 times per month or less
O 1 or more times per week
O or more times per day

Select the frequency of your daily stools, on average
5+ stools per day
3-4 stools per day
1-2 stools per day
O 0 (I do not have stools every day.)

On average, please rate your stool consistency according to the Bristol Stool Chart (image below).
O Type 1
O Type 2
O Type 3
O Type 4
O Type 5
Oype 6
O Type 7 


\begin{tabular}{|c|c|}
\hline Type 1 & $\begin{array}{c}\text { Separate hard lumps, like nuts } \\
\text { (hard to pass) }\end{array}$ \\
\hline Type 2 & $\begin{array}{c}\text { Sausage shaped but lumpy } \\
\text { Type 3 }\end{array}$ \\
\hline Type 4 & $\begin{array}{c}\text { Like a sausage but with cracks on } \\
\text { the surface }\end{array}$ \\
\hline Type 5 & $\begin{array}{c}\text { Soft blobs with clear cut edges } \\
\text { (passed easily) }\end{array}$ \\
\hline Type 6 & $\begin{array}{c}\text { Fluffy pieces with ragged edges, a } \\
\text { mushy stool }\end{array}$ \\
\hline
\end{tabular}

Image reproduced by kind permission of Dr K Heaton, Reader in Medicine, University of Bristol.

www.bladderand bowelfoundation.org

Email: help@bladder and bowelfoundation.org | Telephone: 01926357220

Register ed office address: Pegasus House, Solihull Business Park, Solhull, West Midlands, United Kingdom, B90 4GT. Company number: 10377236. Regstered in the UK

Debriefing Form 
Thank you for participating in our Mindful Eating and Perceived Stress in College Students study!

This study was designed to look at the prevalence of mindful eating behaviors in college students, assess perceived stress levels, and make correlations between mindful eating behaviors and perceived stress levels, including gastrointestinal symptoms. Mindfulness and mindful eating has been shown to have an inverse relationship with stress levels in some populations, but we wanted to assess this relationship in the Winthrop student population.

Stress can sometimes show up in the form of gastrointestinal symptoms such as diarrhea or altered stool consistency, so we gathered information about participants' gastrointestinal symptoms because not many studies look at mindful eating in connection with gastrointestinal symptoms.

This study also seeks to understand how lifestyle factors among Winthrop students relate to the prevalence of mindful eating behaviors, since activities like smoking, alcohol intake, and recreational drug use can be alternative ways of coping with stress.

If you are interested in learning the results of this study, please contact the researchers after May 1, 2021.

\section{Researchers:}

Emily Garrett (garrette3@mailbox.winthrop.edu)

Jessie Hoffman, PhD, RD (hoffmanjb@winthrop.edu)

Hope Lima, PhD, IBCLC (limah@winthrop.edu)

Karin Evans, MA, RD (evansk@winthrop.edu)

Ashley Licata, PhD, RD, CSSD (licataa@winthrop.edu)

Courtney Guenther, PhD (guentherc@winthrop.edu)

Eden Crain (craine2@mailbox.winthrop.edu)

Mika Doyle (doylem3@mailbox.winthrop.edu)

If you have any concerns regarding this study, please contact my faculty advisor, Dr. Jessie Hoffman, or the Office of Grants and Sponsored Research Development.

\section{Faculty_Advisor:}


Dr. Jessie Hoffman

hoffmanjb@winthrop.edu

(803) 323-3961

Grants and Sponsored Research Development

PH: 803-323-2460

If anything about this survey caused you to feel uncomfortable, health and counseling services are available to Winthrop students in the Crawford building. You can reach Counseling Services at (803) 323-2206 or get information at: https://www.winthrop.edu/counseling/

All counseling services are free and confidential.

If you are interested in being entered to win one of two $\$ 25$ Amazon gift cards, please click the following link. Your responses to the current survey will not be tied to this separate entry. https://winthropstudents.qualtrics.com/jfe/form/SV_bdUGM9zgaCUsABf 


\section{Appendix B: Mindful Eating Training Program (METP)}

\begin{tabular}{|c|c|}
\hline Week & Content \\
\hline 1 & $\begin{array}{l}\text { Mindfulness \& Mindful Eating } \\
\text { - Define mindfulness } \\
\text { - Assessment: Mindfulness Self-Assessment } \\
\text { - Define/discuss mindful eating } \\
\text { - Assessment: Mindful Eating Self-Assessment } \\
\text { - } \quad \text { Activity: Deep Breathing }\end{array}$ \\
\hline 2 & $\begin{array}{l}\text { Body Awareness } \\
\text { - Define body awareness } \\
\text { - } \quad \text { Assessment: Body Awareness Self-Assessment } \\
\text { - } \quad \text { Activity: Body Scan } \\
\text { - } \text { Assessment: Body Scan Reflection } \\
\text { Satiety and Body Wisdom } \\
\text { - Activity: Hunger and Fullness Scale } \\
\text { - } \quad \text { Assessment: Hunger and Fullness Scale } \\
\text { - Define satiety } \\
\text { - Define/discuss sensory-specific satiety } \\
\text { - } \quad \text { Activity: The Raisin Meditation }\end{array}$ \\
\hline 3 & $\begin{array}{l}\text { Mindful Movement } \\
\text { - Define/discuss mindful movement } \\
\text { - } \quad \text { Assessment: Mindful Movement Self-Assessment } \\
\text { - Activity: The Walking Meditation } \\
\text { - Assessment: Hunger/Fullness and Movement } \\
\text { Stress \& Emotional Triggers } \\
\text { - Briefly explain the body's stress response } \\
\text { - Briefly explain cortisol's role in the body's stress response } \\
\text { - Define/discuss physical and mental burnout } \\
\text { - } \quad \text { Discuss eating as a coping mechanism } \\
\text { - Activity: Emotion Meditation }\end{array}$ \\
\hline 4 & $\begin{array}{l}\text { Looking Forward: Growth in Mindfulness } \\
\text { - Discuss setting intentions } \\
\text { - } \quad \text { Recap discussion of stress and emotional triggers } \\
\text { - Assessment: Refocusing on Body Awareness } \\
\text { - Discuss mindful snacking } \\
\text { - Protein-Fat-Fiber method } \\
\text { - Incorporating "fun foods" } \\
\text { - Activity: Visualization Meditation }\end{array}$ \\
\hline
\end{tabular}




\section{References}

1. Choi SH, Lee H. Associations of mindful eating with dietary intake pattern, occupational stress, and mental well-being among clinical nurses. Perspectives in Psychiatric Care. 2020;56(2):355-362. doi:10.1111/ppc.12441

2. Ali MM. Occupational stress and its consequences: Implications for health policy and management. Leadership in Health Services. 2014;27(3):224239. doi:10.1108/LHS-07-2013-0032

3. Heckenberg RA, Hale MB, Kent S, Wright BJ. Trait mindfulness and the Effort-Reward Imbalance workplace stress model: Higher trait mindfulness is associated with increased salivary immunoglobulin A. Behavioural Brain Research. 2020;83:126-134.

4. Siegrist J, Starke D, Chandola T, et al. The measurement of effort-reward imbalance at work: European comparisons. Social Science and Medicine. 2004;58(8):1483-1499. doi:10.1016/S0277-9536(03)00351-4

5. Bellingrath S, Kudielka BM. Effort-reward-imbalance and overcommitment are associated with hypothalamus-pituitary-adrenal (HPA) axis responses to acute psychosocial stress in healthy working schoolteachers. Psychoneuroendocrinology. 2008;33(10):1335-1343. doi:10.1016/j.psyneuen.2008.07.008

6. McEwen BS. Protective and damaging effects of stress mediators: Central role of the brain. Dialogues in Clinical Neuroscience. 2006;8(4):367-381. doi:10.31887/dcns.2006.8.4/bmcewen 
7. McEwen BS. Neurobiological and Systemic Effects of Chronic Stress. Chronic Stress. 2017;1. doi:10.1177/2470547017692328

8. Dalton ED, Hammen CL. Independent and relative effects of stress, depressive symptoms, and affect on college students' daily health behaviors. Journal of Behavioral Medicine. 2018;41(6):863-874. doi:10.1007/s10865-018-9945-4

9. Cohen S, Kamarck T, R, Mermelstein. A Global Measure of Perceived Stress. Journal of Health and Social Behavior. 1983;24(4):385-396.

10. Regehr C, Glancy D, Pitts A. Interventions to reduce stress in university students: A review and meta-analysis. Journal of Affective Disorders. 2013;148(1):1-11. doi:10.1016/j.jad.2012.11.026

11. Miller RL, Lucas-thompson RG, Sanchez N, et al. Eating Behaviors Effects of a mindfulness-induction on subjective and physiological stress response in adolescents at-risk for adult obesity. Eating Behaviors. 2021;40(December 2020):101467. doi:10.1016/j.eatbeh.2020.101467

12. Brewer JA, Ruf A, Beccia AL, et al. Can mindfulness address maladaptive eating behaviors? Why traditional diet plans fail and how new mechanistic insights may lead to novel interventions. Frontiers in Psychology. 2018;9(SEP):1-11. doi:10.3389/fpsyg.2018.01418

13. Kerin JL, Webb HJ, Zimmer-Gembeck MJ. Intuitive, mindful, emotional, external and regulatory eating behaviours and beliefs: An investigation of the core components. Appetite. 2019;132(October 2018):139-146. doi:10.1016/j.appet.2018.10.011 
14. Hsu T, Forestell CA. Mindfulness, mood, and food: The mediating role of positive affect. Appetite. 2021;158(October 2020):105001.

doi:10.1016/j.appet.2020.105001

15. Mantzios M, Egan H, Hussain M, Keyte R, Bahia H. Mindfulness, selfcompassion, and mindful eating in relation to fat and sugar consumption: an exploratory investigation. Eating and Weight Disorders. 2018;23(6):833840. doi:10.1007/s40519-018-0548-4

16. Warren JM, Smith N, Ashwell M. A structured literature review on the role of mindfulness, mindful eating and intuitive eating in changing eating behaviours: Effectiveness and associated potential mechanisms. Nutrition Research Reviews. 2017;30(2):272-283. doi:10.1017/S0954422417000154

17. Kristeller JL, Baer RA, Quillian-Wolever R. Mindfulness-Based Approaches to Eating Disorders. In: Mindfulness-Based Approaches To Eating Disorders. ; 2006:75-91.

18. Jordan $\mathrm{CH}$, Wang W, Donatoni L, Meier BP. Mindful eating: Trait and state mindfulness predict healthier eating behavior. Personality and Individual Differences. 2014;68:107-111. doi:10.1016/j.paid.2014.04.013

19. Murray CDR, Flynn J, Ratcliffe L, Jacyna MR, Kamm MA, Emmanuel A v. Effect of acute physical and psychological stress on gut autonomic innervation in irritable bowel syndrome. Gastroenterology. 2004;127(6):1695-1703. doi:10.1053/j.gastro.2004.08.057 
20. Rea K, Dinan TG, Cryan JF. The microbiome: A key regulator of stress and neuroinflammation. Neurobiology of Stress. 2016;4:23-33. doi:10.1016/j.ynstr.2016.03.001

21. Dinan TG, Stilling RM, Stanton C, Cryan JF. Collective unconscious: How gut microbes shape human behavior. Journal of Psychiatric Research. 2015;63:1-9. doi:10.1016/j.jpsychires.2015.02.021

22. Cherpak CE. Mindful Eating: A Review Of How The Stress-DigestionMindfulness Triad May Modulate And Improve Gastrointestinal And Digestive Function. Integrative medicine (Encinitas, Calif). 2019;18(4):4853.

23. Glenny EM, Bulik-Sullivan EC, Tang Q, Bulik CM, Carroll IM. Eating Disorders and the Intestinal Microbiota: Mechanisms of Energy Homeostasis and Behavioral Influence. Current Psychiatry Reports. 2017;19(8). doi:10.1007/s11920-017-0797-3

24. Bonaz B, Bazin T, Pellissier S. The vagus nerve at the interface of the microbiota-gut-brain axis. Frontiers in Neuroscience. 2018;12(FEB):1-9. doi:10.3389/fnins.2018.00049

25. Jenkins TA, Nguyen JCD, Polglaze KE, Bertrand PP. Influence of tryptophan and serotonin on mood and cognition with a possible role of the gut-brain axis. Nutrients. 2016;8(1). doi:10.3390/nu8010056

26. Clark A, Mach N. Exercise-induced stress behavior, gut-microbiota-brain axis and diet: A systematic review for athletes. Journal of the International 
Society of Sports Nutrition. 2016;13(1):1-21. doi:10.1186/s12970-0160155-6

27. Serra D, Almeida LM, Dinis TCP. The Impact of Chronic Intestinal Inflammation on Brain Disorders: the Microbiota-Gut-Brain Axis. Molecular Neurobiology. 2019;56(10):6941-6951. doi:10.1007/s12035-019-1572-8

28. Vodička M, Ergang $\mathrm{P}, \mathrm{Hrnčiŕ} \mathrm{T}$, et al. Microbiota affects the expression of genes involved in HPA axis regulation and local metabolism of glucocorticoids in chronic psychosocial stress. Brain, Behavior, and Immunity. 2018;73. doi:10.1016/j.bbi.2018.07.007

29. Dunlavey C. Introduction to the hypothalamic-pituitary-adrenal axis: healthy and dysregulated stress responses, developmental stress and neurodegeneration. J Undergrad Neurosci Educ. 2018;16(2):R59-R60.

30. Labanski A, Langhorst J, Engler H, Elsenbruch S. Stress and the braingut axis in functional and chronic-inflammatory gastrointestinal diseases: A transdisciplinary challenge. Psychoneuroendocrinology. 2020;111(April 2019). doi:10.1016/j.psyneuen.2019.104501

31. Guilliams T, Edwards L. Chronic stress and the HPA axis: clinical assessment and therapeutic considerations. The Standard. 2010;9(2):1-12.

32. Vivier H, Ross EJ, Cassisi J. Classification of Gastrointestinal Symptom Patterns in Young Adults. BMC Gastroenterology. 2020:1-26. doi:10.21203/rs.2.24044/v1 
33. Zhou X, Guo J, Lu G, et al. Effects of mindfulness-based stress reduction on anxiety symptoms in young people: A systematic review and metaanalysis. Psychiatry Research. 2020;289:113002.

34. Bradford A. Introduction to the Special Issue: Advances in Psychogastroenterology. Journal of Clinical Psychology in Medical Settings. 2020;27(3):429-431. doi:10.1007/s10880-020-09735-3

35. Riehl ME, Kinnucan JA, Chey WD, Stidham RW. Nuances of the psychogastroenterology patient: A predictive model for gastrointestinal quality of life improvement. Neurogastroenterology and Motility. 2019;31(9):1-8. doi:10.1111/nmo.13663

36. O'Loughlin I, Newton-John TRO. 'Dis-comfort eating': An investigation into the use of food as a coping strategy for the management of chronic pain. Appetite. 2019;140(February):288-297.

doi:10.1016/j.appet.2019.05.027

37. O'Reilly GA, Cook L, Sprujit-Metz D, Black DS. Mindfulness-Based Interventions for Obesity-Related Eating Behaviors: A Literature Review. Obes Rev. 2015;15(6):453-461. doi:10.1038/jid.2014.371

38. Smith SM, Vale WW. The role of the hypothalamic-pituitary-adrenal axis in neuroendocrine responses to stress. Dialogues in Clinical Neuroscience. 2006;8(4):383-395. doi:10.31887/dcns.2006.8.4/ssmith

39. Pituitary Gland. Cleveland Clinic website. Accessed March 26, 2021. https://my.clevelandclinic.org/health/articles/21459-pituitary-gland 
40. Lanoix D, Plusquellec P. Adverse effects of pollution on mental health: the stress hypothesis. OA Evidence-Based Medicine. 2013;1(1):1-9. doi:10.13172/2053-2636-1-1-572

41. Kim K, Park SM. Association of muscle mass and fat mass with insulin resistance and the prevalence of metabolic syndrome in Korean adults: a cross-sectional study. Scientific Reports. 2018;8(1):1-8.

doi:10.1038/s41598-018-21168-5

42. Cadegiani FA, Kater CE. Hypothalamic-Pituitary-Adrenal (HPA) Axis Functioning in Overtraining Syndrome: Findings from Endocrine and Metabolic Responses on Overtraining Syndrome (EROS)—EROS-HPA Axis. Sports Medicine - Open. 2017;3(1). doi:10.1186/s40798-017-0113-0

43. Brown KW, Ryan RM. The Benefits of Being Present: Mindfulness and Its Role in Psychological Well-Being. Journal of Personality and Social Psychology. 2003;84(4):822-848. doi:10.1037/0022-3514.84.4.822

44. Kabat-Zinn J. Full Catastrophe Living: Using the Wisdom of Your Body and Mind to Face Stress, Pain, and IIIness. 2nd ed. Random House; 2013.

45. Manigault AW, Woody A, Zoccola PM, Dickerson SS. Trait mindfulness predicts the presence but not the magnitude of cortisol responses to acute stress. Psychoneuroendocrinology. 2018;90:29-34.

46. Bauer-Wu S. Mindfulness meditation. Oncology (Williston Park, NY). 2010;24(10 Suppl):36-40. doi:10.3167/ssi.2018.240205

47. Ditto B, Eclache M, Goldman N. Short-term autonomic and cardiovascular effects of mindfulness body scan meditation. Annals of 
Behavioral Medicine. 2006;32(3):227-234.

doi:10.1207/s15324796abm3203_9

48. Sojcher R, Gould Fogerite S, Perlman A. Evidence and potential mechanisms for mindfulness practices and energy psychology for obesity and binge-eating disorder. Explore: The Journal of Science and Healing. 2012;8(5):271-276. doi:10.1016/j.explore.2012.06.003

49. Greeson JM, Zarrin H, Smoski MJ, et al. Mindfulness Meditation Targets Transdiagnostic Symptoms Implicated in Stress-Related Disorders: Understanding Relationships between Changes in Mindfulness, Sleep Quality, and Physical Symptoms. Evidence-based Complementary and Alternative Medicine. 2018;2018. doi:10.1155/2018/4505191

50. Daubenmier J, Kristeller J, Hecht FM, et al. Mindfulness intervention for stress eating to reduce cortisol and abdominal fat among overweight and obese women: An exploratory randomized controlled study. Journal of Obesity. 2011;2011. doi:10.1155/2011/651936

51. Kennedy LE, Misyak S, Hosig K, Duffey KJ, Ju Y, Serrano E. The Slow Down Program: A mixed methods pilot study of a mindfulness-based stress management and nutrition education program for mothers. Complementary Therapies in Medicine. 2018;38(September 2017):1-6.

doi:10.1016/j.ctim.2018.03.008

52. Hoge EA, Bui E, Palitz SA, et al. The effect of mindfulness meditation training on biological acute stress responses in generalized anxiety 
disorder. Psychiatry Research. 2018;262(November 2016):328-332. doi:10.1016/j.psychres.2017.01.006

53. Pascoe MC, Thompson DR, Jenkins ZM, Ski CF. Mindfulness mediates the physiological markers of stress: Systematic review and meta-analysis. Journal of Psychiatric Research. 2017;95:156-178.

54. Heckenberg RA, Hale MW, Kent S, Wright BJ. An online mindfulnessbased program is effective in improving affect, over-commitment, optimism and mucosal immunity. Physiology and Behavior. 2019;199(October 2018):20-27. doi:10.1016/j.physbeh.2018.11.001

55. Burns JL, Lee RM, Brown LJ. The effect of meditation on self-reported measures of stress, anxiety, depression, and perfectionism in a college population. Journal of College Student Psychotherapy. 2011;25(2):132144. doi:10.1080/87568225.2011.556947

56. Dvořáková K, Kishida M, Li J, et al. Promoting healthy transition to college through mindfulness training with first-year college students: Pilot randomized controlled trial. Journal of American College Health. 2017;65(4):259-267. doi:10.1080/07448481.2017.1278605

57. Collard P, Avny N, Boniwell I. Teaching Mindfulness Based Cognitive Therapy (MBCT) to students: The effects of MBCT on the levels of Mindfulness and Subjective Well-Being. Counselling Psychology Quarterly. 2008;21(4):323-336. doi:10.1080/09515070802602112

58. Moloney RD, O'Mahony SM, Dinan TG, Cryan JF. Stress-induced visceral pain: Toward animal models of irritable-bowel syndrome and 
associated comorbidities. Frontiers in Psychiatry. 2015;6(FEB):1-30. doi:10.3389/fpsyt.2015.00015

59. Theodorou V, Belgnaoui AA, Agostini S, Eutamene H. Effect of commensals and probiotics on visceral sensitivity and pain in irritable bowel syndrome. Gut Microbes. 2014;5(3):430-436.

doi:10.4161/gmic.29796

60. Nightingale S, Sharma A. Functional gastrointestinal disorders in children: What is new? Journal of Paediatrics and Child Health. 2020;56(11):1724-1730. doi:10.1111/jpc.14857

61. Karl PJ, Hatch AM, Arcidiacono SM, et al. Effects of psychological, environmental and physical stressors on the gut microbiota. Frontiers in Microbiology. 2018;9(SEP):1-32. doi:10.3389/fmicb.2018.02013

62. Fukui $\mathrm{H}, \mathrm{Xu} X, \mathrm{Xiwa} \mathrm{H}$. Role of gut microbiota-gut hormone axis in the pathophysiology of functional gastrointestinal disorders. Journal of Neurogastroenterology and Motility. 2018;24(3):367-386. doi:10.5056/jnm18071

63. Li Z, Zhu H, Guo Y, Du X, Qin C. Gut microbiota regulate cognitive deficits and amyloid deposition in a model of Alzheimer's disease. Journal of Neurochemistry. 2020;155(4):448-461. doi:10.1111/jnc.15031

64. Borsom EM, Lee K, Cope EK. Do the bugs in your gut eat your memories? Relationship between gut microbiota and alzheimer's disease. Brain Sciences. 2020;10(11):1-23. doi:10.3390/brainsci10110814 
65. Aho VTE, Houser MC, Pereira PAB, et al. Relationships of gut microbiota, short-chain fatty acids, inflammation, and the gut barrier in Parkinson's disease. Molecular Neurodegeneration. 2021;16:6. doi:10.1101/2020.06.15.20131011

66. $\mathrm{Wu} Q, \mathrm{Xu} Z$, Song S, et al. Gut microbiota modulates stress-induced hypertension through the HPA axis. Brain Research Bulletin. 2020;162(February):49-58. doi:10.1016/j.brainresbull.2020.05.014

67. Simpson CA, Diaz-Arteche C, Eliby D, Schwartz OS, Simmons JG, Cowan CSM. The gut microbiota in anxiety and depression - A systematic review. Clinical Psychology Review. 2021;83(October 2020).

doi:10.1016/j.cpr.2020.101943

68. Bravo JA, Forsythe P, Chew M v., et al. Ingestion of Lactobacillus strain regulates emotional behavior and central GABA receptor expression in a mouse via the vagus nerve. Proceedings of the National Academy of Sciences. 2011;108(38):16050-16055. doi:10.1073/pnas.1102999108

69. Connell M, Shin A, James-Stevenson T, Xu H, Imperiale TF, Herron J. Systematic review and meta-analysis: Efficacy of patented probiotic, VSL\#3, in irritable bowel syndrome. Neurogastroenterology and Motility. 2018;30(12):1-24. doi:10.1111/nmo.13427

70. Bagga D, Aigner CS, Reichert JL, et al. Influence of 4-week multi-strain probiotic administration on resting-state functional connectivity in healthy volunteers. European Journal of Nutrition. 2019;58(5):1821-1827. doi:10.1007/s00394-018-1732-z 
71. Wang H, Lee I-S, Braun C, Enck P. Effect of Probiotics on Central Nervous System Functions in Animals and Humans: A Systematic Review Journal of Neurogastroenterology and Motility. J Neurogastroenterol Motil. 2016;22(4):2093-2879. doi:10.5056/jnm16018

72. Klatzkin RR, Baldassaro A, Rashid S. Physiological responses to acute stress and the drive to eat: The impact of perceived life stress. Appetite. 2019;133(July 2018):393-399. doi:10.1016/j.appet.2018.11.019

73. Epel E, Lapidus R, McEwen B, Brownell K. Stress may add bite to appetite in women: A laboratory study of stress-induced cortisol and eating behavior. Psychoneuroendocrinology. 2001;26(1):37-49.

doi:10.1016/S0306-4530(00)00035-4

74. Cavicchioli M, Movalli M, Maffei C. Difficulties with emotion regulation, mindfulness, and substance use disorder severity: the mediating role of self-regulation of attention and acceptance attitudes. American Journal of Drug and Alcohol Abuse. 2019;45(1):97-107.

doi:10.1080/00952990.2018.1511724

75. Barrington J, Weaver A, Brebner K. Exploring Mindfulness in Relation to Alcohol and Cannabis Use among First Year University Students. College Student Journal. 2019;53(2):163-175.

76. Järvelä-Reijonen E, Karhunen L, Sairanen E, et al. The effects of acceptance and commitment therapy on eating behavior and diet delivered through face-to-face contact and a mobile app: A randomized controlled 
trial. International Journal of Behavioral Nutrition and Physical Activity. 2018;15(1):1-14. doi:10.1186/s12966-018-0654-8

77. Enkema MC, Hallgren KA, Bowen S, Lee CM, Larimer ME. Craving management: Exploring factors that influence momentary craving-related risk of cannabis use among young adults. Addictive Behaviors. 2021;115(October 2020):106750. doi:10.1016/j.addbeh.2020.106750

78. Bronchain J, Raynal P, Chabrol H. Dispositional Mindfulness Profiles and Cannabis Use in Young Adults. Journal of Rational - Emotive and Cognitive - Behavior Therapy. 2020;(0123456789). doi:10.1007/s10942020-00382-z

79. Qi W, Cui L. Eat to avoid negative self-awareness: Locus of control and core self-evaluation as serial mediators in the effect of stress on food intake. Appetite. 2019;143(August):104401.

doi:10.1016/j.appet.2019.104401

80. van Strien T. Causes of Emotional Eating and Matched Treatment of Obesity. Current Diabetes Reports. 2018;18(6). doi:10.1007/s11892-018$1000-x$

81. Frayn M, Livshits S, Knäuper B. Emotional eating and weight regulation: A qualitative study of compensatory behaviors and concerns. Journal of Eating Disorders. 2018;6(1):1-10. doi:10.1186/s40337-018-0210-6

82. Winkens LHH, van Strien T, Brouwer IA, Penninx BWJH, Visser M. Mindful eating and change in depressive symptoms: Mediation by 
psychological eating styles. Appetite. 2019;133(November 2018):204-211. doi:10.1016/j.appet.2018.11.009

83. Monroe JT. Mindful Eating: Principles and Practice. American Journal of Lifestyle Medicine. 2015;9(3):217-220. doi:10.1177/1559827615569682

84. Daubenmier J, Lustig RH, Hecht FM, et al. A new biomarker of hedonic eating? A preliminary investigation of cortisol and nausea responses to acute opioid blockade. Appetite. 2014;74:92-100.

doi:10.1016/j.appet.2013.11.014

85. Mason AE, Lustig RH, Brown RR, et al. Acute responses to opioidergic blockade as a biomarker of hedonic eating among obese women enrolled in a mindfulness-based weight loss intervention trial. Appetite.

2015;91:311-320. doi:doi:10.1016/j.appet.2015.04.062.

86. Satherley R, Howard R, Higgs S. Disordered eating practices in gastrointestinal disorders. Appetite. 2014;84:240-250.

doi:10.1016/j.appet.2014.10.006

87. Sato Y, Fukudo S. Gastrointestinal symptoms and disorders in patients with eating disorders. Clinical Journal of Gastroenterology. 2015;8(5):255263. doi:10.1007/s12328-015-0611-x

88. Framson C, Kristal AR, Schenk JM, Littman AJ, Zeliadt S, Benitez D. Development and Validation of the Mindful Eating Questionnaire. J Am Diet Assoc. 2009;109:1439-1444. doi:10.1016/j.jada.2009.05.006

89. Peitz D, Schulze J, Warschburger P. Getting a Deeper Understanding of Mindfulness in the Context of Eating Behavior: Development and Validation 
of the Mindful Eating Inventory. Appetite. 2020:105039.

doi:10.1016/j.appet.2020.105039

90. Fung TT, Long MW, Hung P, Cheung LWY. An Expanded Model for Mindful Eating for Health Promotion and Sustainability: Issues and Challenges for Dietetics Practice. Journal of the Academy of Nutrition and Dietetics. 2016;116(7):1081-1086. doi:10.1016/j.jand.2016.03.013

91. Loughran T, Harpel T, Vollmer R, Schumacher J. Effectiveness of Intuitive Eating Intervention through Text Messaging among College Students. College Student Journal. 2018;52(2):232-244.

92. Bush HE, Rossy L, Mintz LB, Schopp L. Eat for life: Awork site feasibility study of a novel mindfulness-based intuitive eating intervention. American Journal of Health Promotion. 2014;28(6):380-388.

doi:10.4278/ajhp.120404-QUAN-186

93. Anderson LM, Reilly EE, Schaumberg K, Dmochowski S, Anderson DA. Contributions of mindful eating, intuitive eating, and restraint to BMI, disordered eating, and meal consumption in college students. Eating and Weight Disorders. 2016;21(1):83-90. doi:10.1007/s40519-015-0210-3

94. Kidwell B, Hasford J, Hardesty DM. Emotional ability training and mindful eating. Journal of Marketing Research. 2015. doi:10.1509/jmr.13.0188

95. Kristeller JL, Wolever RQ. Mindfulness-based eating awareness training for treating binge eating disorder: The conceptual foundation. Eating Disorders. 2011;5:282-297. doi:10.1080/10640266.2011.533605 
96. Albers S. Using Mindful Eating to Treat Food Restriction: A Case Study. Eating Disorders. 2011;19:27-107. doi:10.1080/10640266.2011.533609

97. Hepworth NS. A Mindful Eating Group as an Adjunct to Individual Treatment for Eating Disorders: A Pilot Study. Eating Disorders. 2011;19:616. doi:10.1080/10640266.2011.533601

98. Barnes VA, Kristeller JL. Impact of Minfullness-Based Eating Awareness on Diet and Exercise Habits in Adolescents. Int J Complement Altern Med. 2016;3(2). doi:10.15406/ijcam.2016.03.00070.Impact

99. Schaefer JT, Magnuson AB. A review of interventions that promote eating by internal cues. Journal of the Academy of Nutrition and Dietetics. 2014;114(5):734-760. doi:10.1016/j.jand.2013.12.024

100. Dalen J, Smith BW, Shelley BM, Sloan AL, Leahigh L, Begay D. Pilot study: Mindful Eating and Living (MEAL): Weight, eating behavior, and psychological outcomes associated with a mindfulness-based intervention for people with obesity. Complementary Therapies in Medicine. 2010;18(6):260-264. doi:10.1016/j.ctim.2010.09.008

101. Mason AE, Epel ES, Kristeller J, et al. Effects of a mindfulness-based intervention on mindful eating, sweets consumption, and fasting glucose levels in obese adults: data from the SHINE randomized controlled trial. Journal of Behavioral Medicine. 2016;39(2):201-213. doi:10.1007/s10865$015-9692-8$

102. Sarto HM, Barcelo-Soler A, Herrera-Mercadal P, et al. Efficacy of a mindful-eating programme to reduce emotional eating in patients suffering 
from overweight or obesity in primary care settings: A cluster-randomised trial protocol. BMJ Open. 2019;9(11):1-17. doi:10.1136/bmjopen-2019031327

103. Heatherton TF, Baumeister RF. Binge eating as escape from selfawareness. Psychological Bulletin. 1991;110(1):86-108. doi:10.1037//00332909.110.1.86

104. Judge TA, Locke EA, Durham CC, Kluger AN. Dispositional effects on job and life satisfaction: The role of core evaluations. Journal of Applied Psychology. 1998;83(1):17-34. doi:10.1037/0021-9010.83.1.17

105. Presson PK, Benassi VA. Locus of control orientation and depressive symptomatology: A meta-analysis. Journal of Social Behavior and Personality. 1996;11(1):201-212.

106. Kristeller JL, Jordan KD. Mindful eating: Connecting with the wise self, the spiritual self. Frontiers in Psychology. 2018;9(AUG):1-11. doi:10.3389/fpsyg.2018.01271

107. MacKillop J, Anderson EJ. Further psychometric validation of the mindful attention awareness scale (MAAS). Journal of Psychopathology and Behavioral Assessment. 2007;29(4):289-293. doi:10.1007/s10862$007-9045-1$

108. Heaton K, O'Donnell L. An office guide to whole-gut transit time. Patients' recollection of their stool form. J Clin Gastroenterol. 1994;19(1):28-30. doi:doi: 10.1097/00004836-199407000-00008. PMID: 7930429. 
109. AlAteeq DA, Aljhani S, AlEesa D. Perceived stress among students in virtual classrooms during the COVID-19 outbreak in KSA. Journal of Taibah University Medical Sciences. 2020;15(5):398-403. doi:10.1016/j.jtumed.2020.07.004

110. Achterberg M, Dobbelaar S, Boer OD, Crone EA. Perceived stress as mediator for longitudinal effects of the COVID-19 lockdown on wellbeing of parents and children. Scientific Reports. 2021;11(1):1-14. doi:10.1038/s41598-021-81720-8

111. Barajas S, Garra L. Mindfulness and psychopathology: Adaptation of the Mindful Attention Awareness Scale (MAAS) in a Spanish sample. Clinica y Salud. 2014;25(1):49-56. doi:10.1016/S1130-5274(14)70026-X

112. Baiano C, Zappullo I, Conson M, et al. Tendency to worry and fear of mental health during Italy's COVID-19 lockdown. International Journal of Environmental Research and Public Health. 2020;17(16):1-8. doi:10.3390/ijerph17165928

113. Chan Y, So SH wai, Mak ADP, Siah KTH, Chan W, Wu JCY. The temporal relationship of daily life stress, emotions, and bowel symptoms in irritable bowel syndrome-Diarrhea subtype: A smartphone-based experience sampling study. Neurogastroenterology and Motility. 2019;31(3):1-11. doi:10.1111/nmo.13514

114. Mineur Y, Abizaid A, Rao Y, et al. Nicotine Decreases Food Intake Through Activation of POMC Neurons. Science. 2011;332(6035):13301332. doi:10.1016/B978-0-12-397032-9.00001-7 
115. Teoh D, Smith TJ, Song M, Spirtos NM. Care After Chemotherapy:

Peripheral Neuropathy, Cannabis for Symptom Control, and Mindfulness. American Society of Clinical Oncology Educational Book. 2018;(38):469479. doi:10.1200/edbk_209437 